\title{
Outcome and complications of endovascular embolization for vein of Galen malformations: a systematic review and meta-analysis
}

\author{
Jun Yan, MD, PhD, ${ }^{1}$ Jing Wen, MD, PhD, ${ }^{2}$ Roodrajeetsing Gopaul, MD, ${ }^{1}$ Chao-Yuan Zhang, MD, ${ }^{1}$ and \\ Shao-wen Xiao, MD'
}

Departments of ${ }^{1}$ Neurosurgery and ${ }^{2}$ Rheumatism, The First Affiliated Hospital of Guangxi Medical University, Nanning, Guangxi, China

\begin{abstract}
OBJECT There have been many multidisciplinary approaches to the treatment of vein of Galen malformations. Endovascular embolization is the first option for treatment. However, the effects of the treatment remain controversial. The aim of this study is to assess the efficacy and safety of endovascular embolization to treat patients with vein of Galen malformations.
\end{abstract}

METHODS This paper includes a retrospective analysis of a sample of 667 patients who underwent endovascular embolization to treat vein of Galen malformations. The data were obtained through a literature search of PubMed databases. The authors also evaluate the efficacy and safety of the treatment. Mortality within the follow-up period is analyzed. Pooled estimates of proportions with corresponding $95 \% \mathrm{Cls}$ were calculated using raw (i.e., untransformed) proportions (PRAW).

RESULTS In the 34 studies evaluated, neonates accounted for $44 \%$ of the sample $\left(95 \% \mathrm{Cl} 31 \%-57 \% ;\left.\right|^{2}=92.5 \%\right)$, infants accounted for $41 \%\left(95 \% \mathrm{Cl} 30 \%-51 \% ; \mathrm{I}^{2}=83.3 \%\right)$, and children and adults accounted for $12 \%(95 \% \mathrm{Cl} 7 \%-16 \%$; $\left.\mathrm{I}^{2}=52.9 \%\right)$. The meta-analysis revealed that complete occlusion was performed in $57 \%\left(95 \% \mathrm{Cl} 48 \%-65 \% ; \mathrm{I}^{2}=68.2 \%\right)$ of cases, with partial occlusion in $43 \%\left(95 \% \mathrm{Cl} 34 \%-51 \% ; \mathrm{l}^{2}=70.7 \%\right)$. The pooled proportion of patients showing a good outcome was $68 \%\left(95 \% \mathrm{Cl} 61 \%-76 \% ;\left.\right|^{2}=77.8 \%\right)$, while $31 \%$ showed a poor outcome $\left(95 \% \mathrm{Cl} 24 \%-38 \% ;\left.\right|^{2}=75.6 \%\right)$. The proportional meta-analysis showed that postembolization mortality and complications were reported in $10 \%(95 \%$ $\left.\mathrm{Cl} 8 \%-12 \% ; \mathrm{I}^{2}=42.8 \%\right)$ and $37 \%\left(95 \% \mathrm{Cl} 29 \%-45 \% ; \mathrm{I}^{2}=79.1 \%\right)$, respectively. Complications included cerebral hemorrhage, cerebral ischemia, hydrocephalus, leg ischemia, and vessel perforation.

CONCLUSIONS The successful treatment of vein of Galen malformations remains a complex therapeutic challenge. The authors' analysis of clinical history and research literature suggests that vein of Galen malformations treated with endovascular embolization can result in an acceptable mortality rate, complications, and good clinical outcome. Future large-scale, multicenter, randomized trials are necessary to confirm these findings.

http://thejns.org/doi/abs/10.3171/2014.12.JNS141249

KEY WORDS vein of Galen malformation; endovascular embolization; outcome; complications; meta-analysis; vascular malformations; vascular disorders

$\mathrm{V}$ EIN of Galen aneurysmal malformations (VGAMs) are cerebral arteriovenous malformations of the choroidal system draining into the vein of Galen forerunner. Although they represent approximately $1 \%$ of all intracranial vascular lesions, they account for $30 \%$ of vascular malformations in the pediatric age group. ${ }^{7}$ Endovascular embolization is the first option for VGAMs. ${ }^{15,20,30,36}$ The development of endovascular techniques began in the early 1980s. There have been many reports about their use in treating VGAMs since then. Given

ABBREVIATIONS DSA = digital subtraction angiography; VGAM = vein of Galen aneurysmal malformation.

SUBMITTED June 4, 2014. ACCEPTED December 8, 2014.

INCLUDE WHEN CITING Published online July 31, 2015; DOI: 10.3171/2014.12.JNS141249.

DISCLOSURE The authors report no conflict of interest concerning the materials or methods used in this study or the findings specified in this paper. Dr. Yan reports receiving clinical or research support for this study from the Scientific Research Fund of the Ministry of Health of Guangxi Province (project no. Z200926). 
the rarity of VGAMs, most studies have been in the form of case reports. In the largest scale study of 216 patients, Lasjaunias et al. ${ }^{36}$ reported a mortality rate of $10.6 \%$ overall; $74 \%$ of patients were neurologically normal on follow-up. Finally, angiographic analysis confirmed that $55 \%$ of patients achieved complete occlusion.

To date, many studies have been published on the outcome and complication rates of patients following endovascular embolization for case reports of VGAMS. However, prior to this study, no synthesis of these reviews has been reported in an overview. Therefore, in this study, we performed a meta-analysis to provide the most comprehensive evidence possible for age composition, the rate of complete occlusion, clinical outcome, and mortality and complication rates for patients treated with endovascular embolization. Our aim in this study is to help surgeons understand endovascular embolization more comprehensively.

\section{Methods \\ Literature Search}

A literature search was performed independently by 2 investigators using the PubMed databases. Citations for relevant English-language articles published from September 1987 through June 2014 were reviewed. For searches of the PubMed databases, we used the following combination of key words: (vein of Galen malformations OR arteriovenous aneurysms of the vein of Galen OR vein of Galen aneurysm malformations OR aneurysms of the vein of Galen) AND (endovascular embolism OR endovascular therapy). The search was limited to papers published in the English language. All relevant publications were reviewed. The references of retrieved articles were also checked for other relevant publications.

\section{Inclusion Criteria}

Cases included in our meta-analysis were required to meet all of the following criteria: 1) Only patients with vein of Galen aneurysmal malformations (VGAMs) were included and not patients with vein of Galen aneurysmal dilation. 2) Patients had undergone or were undergoing endovascular embolization, without adjuvant radiotherapy or combined surgery after the procedure. 3) Articles included in the analysis focused primarily on the outcome and complications of VGAM. Case reports with fewer than 3 treated patients were excluded.

\section{Data Extraction}

All data were independently abstracted by 2 investigators using a standardized data abstraction form. Inconsistencies were resolved by discussion and consensus. The following information was sought from each article: the first author's name, the year of publication, study country, total number of patients, age at diagnosis, treatment results, postembolization mortality rate, clinical outcome, and any major postembolization complications.

\section{Assessment of Methodological Quality of Included Reviews}

Two of the review authors (J.Y. and J.W.) independently assessed the methodological quality of included reviews using the Cochrane Collaboration's risk of bias tool. These 2 authors rated each study for risk of bias from random sequence generation, allocation concealment, blinding of participants and personnel, blinding of outcome assessment, incomplete outcome data, selective reporting, and other bias. Risk of bias for each domain was rated as high (seriously weakens confidence in the results), low (unlikely to seriously alter the results), or unclear. Discrepancies were resolved through discussion. The primary analysis was repeated without studies at high risk of bias for sequence generation.

\section{Statistical Methods}

The software package $\mathrm{R}$ (version 3.0.2) was adopted for the statistical analysis, with the metaprop function, using raw (i.e., untransformed) proportions (PRAW) to calculate the pooled estimates of proportions with corresponding 95\% CIs. Both the fixed-effects and the random-effects models were taken into account. We used Cochran's Q test to evaluate heterogeneity among the studies. ${ }^{10}$ An $\mathrm{I}^{2}$ value of $<25 \%$ was defined to represent low heterogeneity, a value between $25 \%$ and $50 \%$ was defined as moderate heterogeneity, and a value $>50 \%$ was defined as high heterogeneity. The random-effects model was used if there was high heterogeneity between studies. Otherwise, the fixedeffects model was used. Funnel plots, Begg's test, and Egger's test were used to screen for potential publication bias ( $p<0.05$ was considered statistically significant). ${ }^{47,48}$ All $p$ values adopted were 2 -sided. The quality of the body of evidence for each outcome was judged as high, moderate, or low according to the system developed by the GRADE Working Group (http://www.gradeworkinggroup.org/index.htm).

\section{Results \\ Identification of Eligible Studies}

The literature search identified a total of 34 studies, ${ }^{3-9,12-15,17,20,22-25,28,30,32-42,45,46,50,51}$ which included 667 patients whose VGAMs were treated by endovascular embolization (Fig. 1). The study characteristics are shown in Tables 1 and 2 .

\section{Age at Treatment}

The 667 patients from the 34 studies were divided into 3 groups according to age. The largest group included neonates ( $<1$ month) and accounted for $44 \%$ (95\% CI 31\%$57 \%$; $\left.\mathrm{I}^{2}=92.5 \%\right)$ of cases. Infants $(\geq 1$ month to $<2$ years) accounted for $41 \%$ (95\% CI $30 \%-51 \%$; $\left.\mathrm{I}^{2}=83.3 \%\right)$, and children and adults ( $\geq 2$ years) accounted for $12 \%$ (95\% CI $\left.7 \%-16 \% ; \mathrm{I}^{2}=52.9 \%\right)($ Table 3$)$.

\section{Treatment Results}

Of the 34 studies, all reported complete data regarding the extent of embolization and were included in this analysis. The complete occlusion of the lesion was initially judged by the surgeon and confirmed by digital subtraction angiography (DSA) or CT angiography scans after embolization. Complete occlusion was achieved in 57\% 


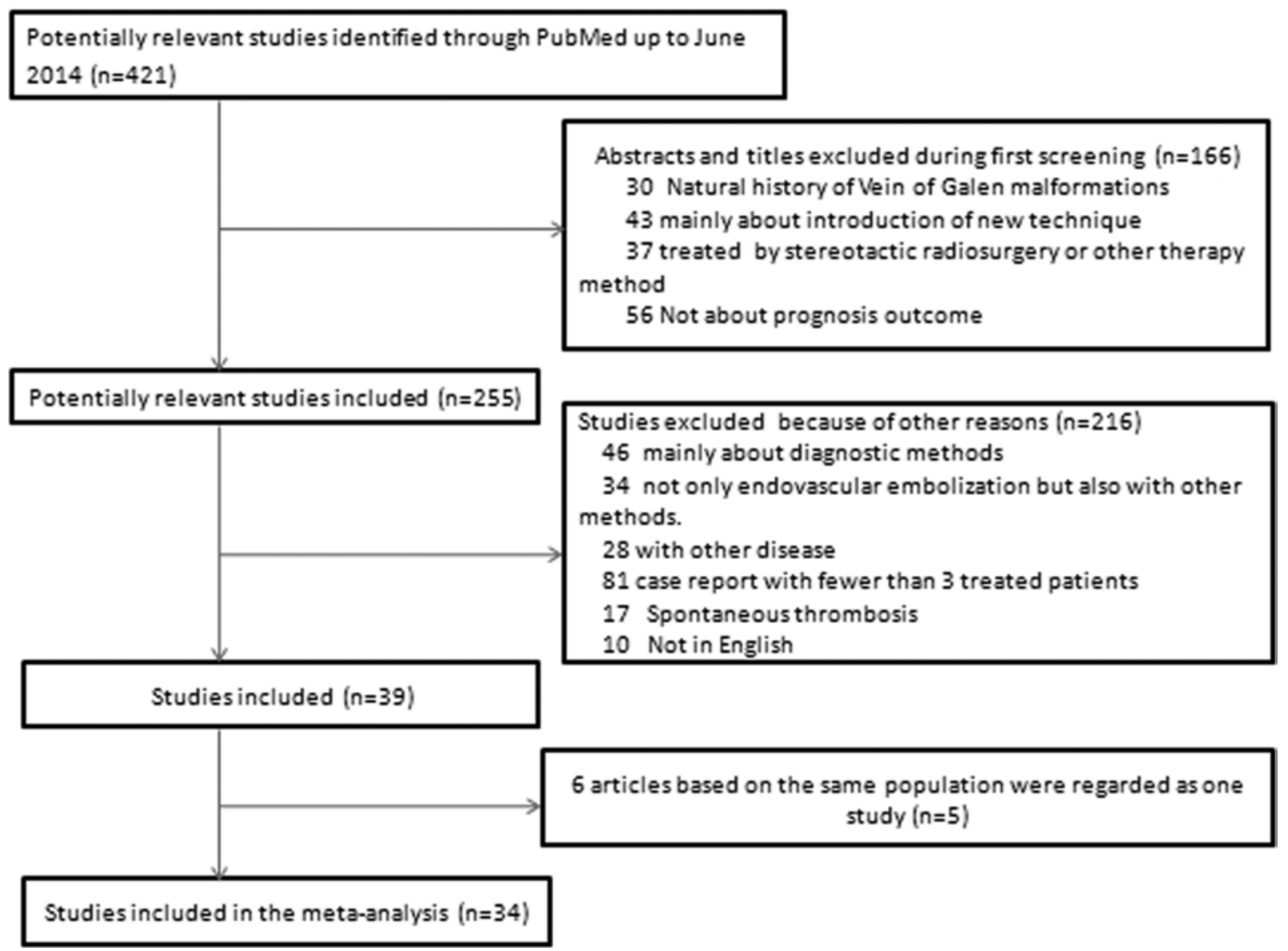

FIG. 1. Flowchart of review process, process of identification, and selection of studies for inclusion in the meta-analysis.

$\left(95 \%\right.$ CI $\left.48 \%-65 \% ; \mathrm{I}^{2}=68.2 \%\right)$ of cases; partial occlusion was attained in $43 \%\left(95 \%\right.$ CI $\left.34 \%-51 \% ; \mathrm{I}^{2}=70.7 \%\right)$ of cases.

\section{Number of Sessions and Postembolization Complications for Patients Who Underwent Endovascular Therapy}

A total of 18 papers (164 patients) were included in the analysis (Table 4; due to a lack of data on cerebral hemorrhage and venous thrombosis, the study by Meila et al. ${ }^{40}$ was not included in this analysis). We present the number of processes and postembolization complications for patients who underwent endovascular therapy (Table 5). As expected, patients with a completely occluded fistula, who were treated in 1 stage, had the highest incidence of complications (cerebral hemorrhage [32\%] and venous thrombosis [27\%]). Patients with completely occluded fistulas who were treated 2 or 3 times had considerably fewer complications (cerebral hemorrhage [21\%] and venous thrombosis [24\%]). Patients treated more than 3 times had the lowest incidence of complications (cerebral hemorrhage [18\%] and venous thrombosis [24\%]).

\section{Follow-Up Assessment and Outcome}

The follow-up period ranged from 0 to 148 months, with a mean of 63 months. The outcome score was graded on a 5-point scale according to Jones et al. ${ }^{30}$ ranging from 0 (death) to 4 (normal). A score of 1 indicates severe neurological impairment, requiring intensive supportive care. A score of 2 indicates moderate neurological impairment affecting activities of daily living and requiring significant support. A score of 3 indicates mild neurological impairment and requires little support in daily life. The developmental milestones were evaluated as well.

Clinical outcome was classified as good for scores between 4 and 3 (neurologically normal and mild developmental delays), and poor for scores of 2,1 , and 0 (moderate developmental delays, severe developmental delays, and death). However, not every study provided scores to assess grading; therefore, we classified the clinical outcome as good or poor according to the clinical symptoms of patients if a score was lacking. Patient clinical outcome was analyzed in all 34 studies. The pooled proportion of patients showing a good outcome was 68\% (95\% CI 61\%$76 \% ; \mathrm{I}^{2}=77.8 \%$ ) (Fig. 2); a poor outcome was shown by $31 \%$ (95\% CI 24\%-38\%; I $\mathrm{I}^{2}=75.6 \%$ ) (Fig. 3).

\section{Mortality}

We analyzed the overall $16 \%$ mortality rate $(95 \%$ CI $12 \%-21 \% ; \mathrm{I}^{2}=59.9 \%$ ), including the $12 \%$ mortality rate of embolized patients (95\% CI 8\%-16\%; $\mathrm{I}^{2}=42.8 \%$ ) (Fig. 4) and the $47 \%$ mortality rate of nonembolized patients $(95 \%$ 
TABLE 1. Outcome of studies included in the meta-analysis

\begin{tabular}{|c|c|c|c|c|c|c|c|c|c|c|c|}
\hline \multirow[b]{2}{*}{ Authors \& Year } & \multirow[b]{2}{*}{ Country } & \multirow[b]{2}{*}{ Total } & \multicolumn{3}{|c|}{ Age Group at Treatment } & \multicolumn{2}{|c|}{ Treatment Result } & \multicolumn{2}{|c|}{ Mortality } & \multicolumn{2}{|c|}{$\begin{array}{c}\text { Clinical } \\
\text { Outcome }\end{array}$} \\
\hline & & & $\begin{array}{c}\text { Neonate } \\
(<1 \mathrm{mo})\end{array}$ & $\begin{array}{c}\text { Infant }(\geq 1 \mathrm{mo} \\
\text { to }<2 \mathrm{yrs})\end{array}$ & $\begin{array}{l}\text { Child or Adult } \\
\qquad(\geq 2 \text { yrs })\end{array}$ & $\begin{array}{l}\text { Complete } \\
\text { Occlusion }\end{array}$ & $\begin{array}{l}\text { Partial } \\
\text { Occlusion }\end{array}$ & $\begin{array}{l}\text { Technical } \\
\text { Mortality }\end{array}$ & Other & Good & Poor \\
\hline Ellis et al., 2012 & US & 5 & 2 & 2 & 1 & 4 & 1 & 0 & 0 & 5 & 0 \\
\hline Berenstein et al., 2012 & US & 9 & 9 & 0 & 0 & 6 & 2 & 1 & 0 & 6 & 3 \\
\hline Meila et al., 2012 & Germany & 14 & 8 & 6 & 0 & 11 & 3 & 0 & 1 & 11 & 3 \\
\hline Li et al., 2011 & Canada & 21 & 7 & 10 & 4 & 4 & 17 & 2 & 2 & 10 & 11 \\
\hline Moon et al., 2011 & Korea & 5 & 3 & 2 & 0 & 1 & 4 & 2 & 0 & 3 & 2 \\
\hline Pongpech et al., 2010 & Thailand & 5 & 0 & 4 & 1 & 2 & 3 & 0 & 0 & 3 & 2 \\
\hline Zuccaro et al., 2010 & Argentina & 8 & 4 & 4 & 0 & 5 & 3 & 0 & 1 & 5 & 3 \\
\hline Heuer et al., 2010 & US & 11 & 7 & 3 & 1 & 7 & 6 & 1 & 1 & 8 & 4 \\
\hline Hassan et al., 2010 & Egypt & 8 & 0 & 5 & 3 & 6 & 1 & 0 & 0 & 7 & 1 \\
\hline McSweeney et al., 2010 & England & 28 & 21 & 3 & 4 & 11 & 17 & 1 & 1 & 20 & 8 \\
\hline Lasjaunias et al., 2006 & France & 216 & 23 & 153 & 40 & 119 & 97 & 3 & 20 & 173 & 43 \\
\hline Gupta et al., 2006 & India & 15 & 0 & 6 & 9 & 13 & 2 & 0 & 0 & 15 & 0 \\
\hline Wong et al., 2006 & Australia & 9 & 9 & 0 & 0 & 5 & 4 & 1 & 2 & 4 & 5 \\
\hline Fullerton et al., 2003 & US & 27 & 21 & 5 & 1 & 21 & 6 & 0 & 4 & 23 & 4 \\
\hline Jones et al., 2002 & US & 13 & 8 & 4 & 1 & NA & NA & 1 & 4 & 7 & 6 \\
\hline Chevret et al., 2002 & France & 18 & 18 & 0 & 0 & NA & NA & 0 & 6 & 10 & 8 \\
\hline Frawley et al., 2002 & Australia & 9 & 9 & 0 & 0 & NA & NA & 0 & 3 & 6 & 3 \\
\hline Komiyama et al., 2001 & Japan & 6 & 3 & 1 & 0 & NA & NA & 1 & 2 & 1 & 3 \\
\hline Mitchell et al., 2001 & Australia & 5 & 4 & 1 & 0 & 3 & 2 & 1 & 1 & 3 & 2 \\
\hline Campi et al., 1998 & France & 3 & 2 & 1 & 0 & 2 & 1 & 1 & 0 & 2 & 1 \\
\hline Halbach et al., 1998 & US & 8 & 2 & 6 & 0 & 4 & 4 & 0 & 0 & 8 & 0 \\
\hline lizuka et al., 1998 & Japan & 3 & 2 & 1 & 0 & NA & NA & 0 & 2 & 1 & 2 \\
\hline Borthne et al., 1997 & Norway & 14 & 5 & 5 & 4 & NA & NA & 1 & 3 & 10 & 4 \\
\hline Lasjaunias et al., 1995 & France & 52 & 31 & 16 & 5 & NA & NA & 3 & 10 & 31 & 21 \\
\hline Rodesch et al., 1994 & France & 12 & 0 & 12 & 0 & 8 & 4 & 0 & 0 & 8 & 4 \\
\hline Lylyk et al., 1993 & US & 28 & 11 & 13 & 4 & 13 & 15 & 3 & 2 & 17 & 11 \\
\hline Friedman et al., 1993 & US & 11 & 11 & 0 & 0 & NA & NA & 0 & 0 & 8 & 3 \\
\hline Lasjaunias et al., 1991 & Canada & 34 & 13 & 14 & 7 & 16 & 18 & 1 & 1 & 18 & 16 \\
\hline $\begin{array}{l}\text { Garcia-Monaco et al., } \\
1991\end{array}$ & France & 22 & 19 & 7 & 4 & 16 & 6 & 2 & 0 & 20 & 2 \\
\hline Casasco et al., 1991 & Argentina & 7 & 1 & 5 & 1 & 5 & 2 & 1 & 0 & 7 & 0 \\
\hline Ciricillo et al., 1990 & US & 8 & 8 & 0 & 0 & NA & NA & 1 & 1 & 2 & 6 \\
\hline Lasjaunias et al., 1989 & France & 15 & NA & NA & NA & 10 & 5 & 0 & 2 & 4 & 11 \\
\hline Hanner et al., 1988 & US & 15 & NA & NA & NA & 6 & 8 & 1 & 2 & 12 & 3 \\
\hline Burrows et al., 1987 & Canada & 3 & 1 & 1 & 1 & 0 & 3 & 1 & 0 & 1 & 2 \\
\hline
\end{tabular}

$\mathrm{NA}=$ not available.

CI $24 \%-69 \% ; \mathrm{I}^{2}=90.7 \%$ ). At the same time, we analyzed the causes of death with the embolized patients, including the technical reasons related to embolization $(2 \%$ [95\% CI $1 \%-3 \%$ ], $\mathrm{I}^{2}=0 \%$ ), such as cerebral hemorrhage, broken catheter, catheter perforation, intractable congestive heart failure due to failed embolization, and other causes (comorbidities) (6\% [95\% CI 4\%-8\%], $\left.\mathrm{I}^{2}=33.7 \%\right)$, such as persistent heart failure, subdural hematoma, pulmonary infarct, progressive neurological deterioration, rejected treatment, melting brain syndrome, severe seizures, and multiple organ failure (Table 6).

\section{Postembolization Complications}

The analysis included the following postembolization complications: cerebral hematoma, cerebral ischemia, macrocephaly or hydrocephalus, mental retardation or developmental delay, leg ischemia, and vessel perforation. The proportional meta-analysis showed a pooled proportion of 37\% (95\% CI 29\%-45\%; $\mathrm{I}^{2}=79.1 \%$ ) (Fig. 5).

Cerebral hemorrhage was reported most frequently as a postembolization complication. Cerebral hemorrhage data were available for all studies. The proportional metaanalysis showed that a pooled proportion of 5\% $(95 \% \mathrm{CI}$ 
TABLE 2. Complications in studies included in the meta-analysis

\begin{tabular}{|c|c|c|c|c|c|c|c|c|c|c|}
\hline Authors \& Year & Country & Total & Complications & $\begin{array}{c}\text { Cerebral } \\
\text { Hemorrhage }\end{array}$ & $\begin{array}{l}\text { Cerebral } \\
\text { Ischemia }\end{array}$ & Hydroceph & $\begin{array}{c}\text { Developmental } \\
\text { Delay }\end{array}$ & $\begin{array}{c}\text { Leg } \\
\text { Ischemia }\end{array}$ & $\begin{array}{c}\text { Vessel } \\
\text { Perforation }\end{array}$ & $\begin{array}{c}\mathrm{FU} \\
(\mathrm{mos})\end{array}$ \\
\hline Ellis et al., 2012 & US & 5 & 3 & 2 & 1 & 0 & NA & 0 & 0 & $2-97$ \\
\hline Berenstein et al., 2012 & US & 9 & 4 & 4 & 3 & 0 & NA & 1 & 1 & NA \\
\hline Meila et al., 2012 & Germany & 14 & 4 & 2 & 0 & 0 & NA & 0 & 4 & $1-148$ \\
\hline Li et al., 2011 & Canada & 21 & 11 & 1 & 0 & 4 & 7 & 0 & NA & $1-24$ \\
\hline Moon et al., 2011 & Korea & 5 & 2 & 2 & 0 & 0 & 0 & NA & NA & $0-72$ \\
\hline Pongpech et al., 2010 & Thailand & 5 & 2 & 0 & 1 & 0 & NA & 0 & 2 & $12-108$ \\
\hline Zuccaro et al., 2010 & Argentina & 8 & 1 & 1 & 0 & 1 & NA & 0 & 0 & NA \\
\hline Heuer et al., 2010 & US & 11 & 4 & 3 & 1 & 0 & NA & 0 & 0 & $0-144$ \\
\hline Hassan et al., 2010 & Egypt & 8 & 1 & 0 & 0 & 0 & NA & 1 & 0 & NA \\
\hline McSweeney et al., 2010 & England & 28 & 10 & 3 & 8 & 6 & NA & 2 & 3 & $0-60$ \\
\hline Lasjaunias et al., 2006 & France & 216 & 21 & 11 & 0 & 0 & 13 & 8 & 7 & $0-12$ \\
\hline Gupta et al., 2006 & India & 15 & 6 & 2 & 1 & 0 & 1 & 1 & 0 & $1-12$ \\
\hline Wong et al., 2006 & Australia & 9 & 5 & 1 & 4 & 0 & 1 & NA & 0 & $0-60$ \\
\hline Fullerton et al., 2003 & US & 27 & 13 & 0 & 0 & 0 & 9 & 3 & NA & $0-54$ \\
\hline Jones et al., 2002 & US & 13 & 6 & 3 & NA & 6 & NA & 2 & NA & $3-108$ \\
\hline Chevret et al., 2002 & France & 18 & 9 & NA & NA & NA & 9 & NA & NA & 63 \\
\hline Frawley et al., 2002 & Australia & 9 & 4 & 0 & 3 & 0 & 1 & NA & NA & $1-48$ \\
\hline Komiyama et al., 2001 & Japanese & 6 & 2 & 1 & 0 & 0 & 0 & 0 & 1 & $6-144$ \\
\hline Mitchell et al., 2001 & Australia & 5 & 0 & 0 & 0 & 0 & 0 & 0 & NA & $0-29$ \\
\hline Campi et al., 1998 & France & 3 & 1 & 1 & NA & 1 & 1 & 2 & NA & $13-39$ \\
\hline Halbach et al., 1998 & US & 8 & 2 & 2 & 0 & 2 & 1 & 0 & NA & $3-105$ \\
\hline lizuka et al., 1998 & Japanese & 3 & 2 & 0 & 0 & 0 & 2 & NA & NA & 5 \\
\hline Borthne et al., 1997 & Norway & 14 & 8 & 0 & 2 & 7 & NA & 1 & NA & $1-72$ \\
\hline Lasjaunias et al., 1995 & France & 52 & 21 & 3 & 4 & 0 & 11 & 3 & NA & 120 \\
\hline Rodesch et al., 1994 & France & 12 & 4 & 0 & 0 & 2 & 4 & 2 & NA & 6 \\
\hline Lylyk et al., 1993 & US & 28 & 11 & 3 & 2 & 4 & 4 & 0 & 2 & $12-24$ \\
\hline Friedman et al., 1993 & US & 11 & 3 & 2 & 6 & 4 & 3 & 0 & NA & $1-30$ \\
\hline Lasjaunias et al., 1991 & Canada & 34 & 21 & 2 & NA & 1 & 3 & 1 & NA & $6-24$ \\
\hline $\begin{array}{l}\text { Garcia-Monaco et al., } \\
1991\end{array}$ & France & 22 & 3 & 2 & 0 & 0 & 0 & NA & NA & 6 \\
\hline Casasco et al., 1991 & Argentina & 7 & 0 & 0 & 0 & 0 & 0 & 0 & 1 & $4-23$ \\
\hline Ciricillo et al., 1990 & US & 8 & 6 & 2 & 5 & 1 & 3 & 0 & 1 & $7-62$ \\
\hline Lasjaunias et al., 1989 & France & 15 & 8 & 3 & 3 & 2 & 1 & NA & 0 & NA \\
\hline Hanner et al., 1988 & US & 15 & 5 & 1 & 2 & 1 & 0 & NA & 0 & NA \\
\hline Burrows et al., 1987 & Canada & 3 & 2 & 1 & 1 & 0 & NA & 0 & NA & $7-72$ \\
\hline
\end{tabular}

$\mathrm{FU}=$ follow-up; Hydroceph = hydrocephalus.

$4 \%-7 \% ; \mathrm{I}^{2}=16.4 \%$ ) of included patients suffered a cerebral hemorrhage. Of the 34 studies examined, 30 reported complete data regarding cerebral ischemia and were subsequently included in this analysis. The rate of cerebral ischemia in these studies was 6\% (95\% CI 3\%-10\%; $\mathrm{I}^{2}$ $=60.8 \%$ ). Hydrocephalus was analyzed in 33 of the 34 studies. The pooled proportion of hydrocephalus was $0 \%$ (95\% CI 0\%-1\%; $\left.\mathrm{I}^{2}=47.7 \%\right)$. Developmental delay was analyzed in 23 of the 34 studies. The pooled proportion of developmental delay was $12 \%$ (95\% CI 8\%-17\%; $\mathrm{I}^{2}=$ 64.2\%). Leg ischemia was analyzed in 26 of the 34 studies. The pooled proportion of leg ischemia was $3 \%(95 \%$
CI $2 \%-5 \% ; \mathrm{I}^{2}=0 \%$ ). Vessel perforation was analyzed in 17 of the 34 studies. The pooled proportion of vessel perforation was $3 \%\left(95 \%\right.$ CI $\left.1 \%-5 \% ; \mathrm{I}^{2}=0 \%\right)$.

Main Outcome Criteria (Mortality, Good/Poor Clinical Outcome, Complications) Over the 1980s, 1990s, and 2000s

There were 34 papers included in this analysis. Main outcomes were, first, the mortality rate of embolized patients during the 1980s, 1990s, and 2000s were 17\%, 12\%, and $12 \%$, respectively. Second, the complication rate of embolized patients over the 1980s, 1990s, and 2000s were $45 \%, 38 \%$, and $35 \%$, respectively. Third, the good clinical 
TABLE 3. Meta-analysis of the outcome and complications of endovascular embolization for vein of Galen malformations

\begin{tabular}{|c|c|c|c|c|c|c|c|c|c|}
\hline \multirow[b]{2}{*}{ Variable } & \multirow[b]{2}{*}{$\begin{array}{l}\text { No. of } \\
\text { Events }\end{array}$} & \multirow[b]{2}{*}{ Total } & \multirow[b]{2}{*}{$\begin{array}{l}\text { Proportion } \\
(95 \% \mathrm{Cl})\end{array}$} & \multirow[b]{2}{*}{ Model } & \multicolumn{2}{|c|}{ Test of Heterogeneity* } & \multicolumn{2}{|c|}{ p Publication Bias } & \multirow[b]{2}{*}{$\begin{array}{l}\text { Quality of Evidence } \\
\text { (GRADE) }\end{array}$} \\
\hline & & & & & $1^{2}$ & $p$ Value & $\begin{array}{l}\text { Egger's } \\
\text { Test† }\end{array}$ & $\begin{array}{l}\text { Begg's } \\
\text { Testł }\end{array}$ & \\
\hline \multicolumn{10}{|l|}{ Age at treatment } \\
\hline Neonate $(<1 \mathrm{mo})$ & 198 & 561 & $44 \%(31-57 \%)$ & $\mathrm{R}$ & $92.5 \%$ & $<0.0001$ & 0.003829 & 0.9069 & Very low \\
\hline Infant ( $\geq 1$ mo to $<2$ yrs) & 278 & 561 & $41 \%(30-51 \%)$ & $\mathrm{R}$ & $83.3 \%$ & $<0.0001$ & 0.1051 & 0.1819 & Moderate \\
\hline Child or adult ( $\geq 2$ yrs) & 91 & 561 & $12 \%(7-16 \%)$ & $\mathrm{R}$ & $52.9 \%$ & 0.0011 & 0.6705 & 0.1671 & Moderate \\
\hline \multicolumn{10}{|l|}{ Treatment result } \\
\hline Complete occlusion & 298 & 533 & $57 \%(48-65 \%)$ & $\mathrm{R}$ & $68.2 \%$ & $<0.0001$ & 0.9470 & 0.6072 & Moderate \\
\hline Partial occlusion & 234 & 533 & $43 \%(34-51 \%)$ & $\mathrm{R}$ & $70.7 \%$ & $<0.0001$ & 0.9327 & 0.674 & Moderate \\
\hline \multicolumn{10}{|l|}{ Clinical outcome } \\
\hline Good & 469 & 667 & $68 \%(61-76 \%)$ & $\mathrm{R}$ & $77.8 \%$ & $<0.0001$ & 0.001599 & 0.01427 & Very low \\
\hline Poor & 197 & 667 & $31 \%(24-38 \%)$ & $\mathrm{R}$ & $75.6 \%$ & $<0.0001$ & 0.001756 & 0.03252 & Very low \\
\hline Overall mortality & 136 & 775 & $16 \%(12-21 \%)$ & $\mathrm{R}$ & $59.9 \%$ & $<0.0001$ & 0.0002953 & 0.02227 & Very low \\
\hline Nonembolized patients & 36 & 101 & $47 \%(24-69 \%)$ & $\mathrm{R}$ & $90.7 \%$ & $<0.0001$ & 0.1659 & 0.5507 & Moderate \\
\hline Embolized patients & 99 & 667 & $10 \%(8-12 \%)$ & $\mathrm{F}$ & $42.8 \%$ & 0.005 & 0.002346 & 0.0007542 & Very low \\
\hline Technical mortality & 29 & 667 & $2 \%(1-3 \%)$ & $\mathrm{F}$ & $0 \%$ & 0.9163 & 0.0002155 & $1 e-04$ & Very low \\
\hline Other reasons & 71 & 667 & $6 \%(4-8 \%)$ & $\mathrm{F}$ & $33.7 \%$ & 0.0306 & 0.03837 & 0.001484 & Very low \\
\hline Complications & 205 & 667 & $37 \%(29-45 \%)$ & $\mathrm{R}$ & $79.1 \%$ & $<0.0001$ & $3.467 e-06$ & 0.7892 & Low \\
\hline Cerebral hemorrhage & 58 & 649 & $5 \%(4-7 \%)$ & $\mathrm{F}$ & $16.4 \%$ & 0.2062 & 0.0001468 & $7.628 \mathrm{e}-05$ & Very low \\
\hline Cerebral ischemia & 47 & 599 & $6 \%(3-10 \%)$ & $\mathrm{R}$ & $60.8 \%$ & $<0.0001$ & $3.196 e-05$ & $4.939 \mathrm{e}-05$ & Very low \\
\hline Hydrocephalus & 42 & 649 & $0 \%(0-1 \%)$ & $\mathrm{F}$ & $47.7 \%$ & 0.0014 & 0.00017 & $9.377 e-06$ & Very low \\
\hline Developmental delay & 74 & 549 & $12 \%(8-17 \%)$ & $\mathrm{R}$ & $64.2 \%$ & $<0.0001$ & 0.004516 & 0.007496 & Very low \\
\hline Leg ischemia & 27 & 571 & $3 \%(2-5 \%)$ & $\mathrm{F}$ & $0 \%$ & 0.8258 & 0.2076 & 0.02689 & Moderate \\
\hline Vessel perforate & 22 & 407 & $3 \%(1-5 \%)$ & $\mathrm{F}$ & $0 \%$ & 0.5393 & 0.1073 & 0.001202 & Moderate \\
\hline
\end{tabular}

$\mathrm{F}=$ fixed-effects model; $\mathrm{R}=$ random-effects model.

* $p<0.10$ is considered statistically significant for $Q$ statistics; $I^{2}$ is interpreted as the proportion of total variation contributed by between-study variation.

$\dagger$ Egger's test to evaluate publication bias, $p<0.05$ is considered statistically significant.

$\ddagger$ Begg's test to evaluate publication bias, $p<0.05$ is considered statistically significant.

outcome rate of embolized patients over the 1980s, 1990s, and 2000 s was $49 \%, 70 \%$, and $70 \%$, respectively, whereas the poor clinical outcome rate of embolized patients over the 1980 s, 1990 s, and 2000 s was $51 \%, 30 \%$, and $28 \%$, respectively (Table 7).

\section{Methodological Quality of Included Reviews}

The quality of the 34 studies retained for analysis can be found in the text of the present paper. It shows the risk of bias ratings for each trial. Twenty-seven trials were at high risk of bias for sequence generation, and these included 433 participants. Twelve studies were at high risk of bias because of inadequate allocation concealment, and 22 were unclear. Lack of blinding of assessors created a high risk of bias in 29 studies, but it was unclear if assessors were blinded in 5 trials. Seventeen studies were at high risk of bias for failing to blind project staff, and 17 trials were unclear on this issue. At the trial level, only one was at high risk of bias for missing data and one was unclear, but the complete outcome data were described in 32 trials, though missing data for the primary outcome was not a concern. Nineteen studies seemed to be completely free from selective outcome reporting (low risk of bias). Thirteen studies were not completely free from selective outcome reporting (high risk of bias). It was unclear if 2 trials reported all outcomes, but the primary outcome was known for almost all participants in the review. To test for bias, the primary analysis was repeated without studies at high risk of bias for sequence generation (Figs. 6 and 7).

\section{Grade of Evidence}

The quality of the evidence was rated as moderate for 7 , low for 1 , and very low for 11 . Risk of bias and publication bias introduced by study design was the reason for downgrading the quality from high to very low, with the absence of blinding of outcome assessors being the most serious potentially avoidable concern.

\section{Heterogeneity}

As is shown, there was significant statistical heterogeneity for age at diagnosis: neonates $\left(\mathrm{p}<0.0001, \mathrm{I}^{2}=\right.$ $92.5 \%)$; infant $\left(\mathrm{p}<0.0001, \mathrm{I}^{2}=83.3 \%\right)$; and children and adults $\left(\mathrm{p}=0.0011, \mathrm{I}^{2}=52.9 \%\right)$. In the treatment results, heterogeneity was calculated as complete occlusion ( $\mathrm{p}<$ $\left.0.0001, \mathrm{I}^{2}=68.2 \%\right)$ and partial occlusion $\left(\mathrm{p}<0.0001, \mathrm{I}^{2}=\right.$ $70.7 \%$ ). In terms of clinical outcome, the results were good clinical outcome $\left(\mathrm{p}<0.0001, \mathrm{I}^{2}=77.8 \%\right)$ and poor clinical outcome ( $\left.\mathrm{p}<0.0001, \mathrm{I}^{2}=75.6 \%\right)$. In the heterogeneity for 
TABLE 4. Number of sessions and postembolization complications of included studies

\begin{tabular}{|c|c|c|c|c|c|c|c|c|c|c|c|}
\hline \multirow[b]{2}{*}{ Authors \& Year } & \multirow[b]{2}{*}{ Country } & \multirow[b]{2}{*}{ Total } & \multicolumn{3}{|c|}{1 Session } & \multicolumn{3}{|c|}{ 2-3 Sessions } & \multicolumn{3}{|c|}{$>3$ Sessions } \\
\hline & & & No. of Patients & $\mathrm{CH}$ & VT & No. of Patients & $\mathrm{CH}$ & VT & No. of Patients & $\mathrm{CH}$ & VT \\
\hline Ellis et al., 2012 & US & 5 & 1 & 1 & 0 & 4 & 1 & 1 & 0 & 0 & 0 \\
\hline Berenstein et al., 2012 & US & 9 & 1 & 1 & 0 & 3 & 1 & 0 & 5 & 2 & 1 \\
\hline Meila et al., 2012 & Germany & 14 & 1 & NA & NA & 6 & NA & NA & 7 & NA & NA \\
\hline Li et al., 2011 & Canada & 21 & NA & NA & NA & NA & NA & NA & NA & NA & NA \\
\hline Moon et al., 2011 & Korea & 5 & 1 & 0 & 0 & 2 & 1 & 0 & 2 & 1 & 0 \\
\hline Pongpech et al., 2010 & Thailand & 5 & 3 & 1 & 1 & 0 & 0 & 0 & 2 & 0 & 1 \\
\hline Zuccaro et al., 2010 & Argentina & 8 & 1 & 0 & 0 & 7 & 2 & 0 & 0 & 0 & 0 \\
\hline Heuer et al., 2010 & US & 13 & 6 & 2 & 2 & 5 & 2 & 1 & 0 & 0 & 0 \\
\hline Hassan et al., 2010 & Egypt & 8 & 7 & 1 & 2 & 1 & 0 & 0 & 0 & 0 & 0 \\
\hline McSweeney et al., 2010 & England & 28 & 9 & 3 & 3 & 12 & 4 & 6 & 7 & 1 & 2 \\
\hline Lasjaunias et al., 2006 & France & 216 & NA & NA & NA & NA & NA & NA & NA & NA & NA \\
\hline Gupta et al., 2006 & India & 15 & NA & NA & NA & NA & NA & NA & NA & NA & NA \\
\hline Wong et al., 2006 & Australia & 9 & 2 & 1 & 1 & 5 & 1 & 2 & 1 & 0 & 1 \\
\hline Fullerton et al., 2003 & US & 27 & NA & NA & NA & NA & NA & NA & NA & NA & NA \\
\hline Jones et al., 2002 & US & 13 & NA & NA & NA & NA & NA & NA & NA & NA & NA \\
\hline Chevret et al., 2002 & France & 18 & NA & NA & NA & NA & NA & NA & NA & NA & NA \\
\hline Frawley et al., 2002 & Australia & 9 & 2 & 1 & 1 & 4 & 0 & 0 & 3 & 1 & 1 \\
\hline Komiyama et al., 2001 & Japan & 6 & NA & NA & NA & NA & NA & NA & NA & NA & NA \\
\hline Mitchell et al., 2001 & Australia & 5 & 1 & 1 & 0 & 3 & 0 & 1 & 1 & 0 & 0 \\
\hline Campi et al., 1998 & France & 3 & NA & NA & NA & NA & NA & NA & NA & NA & NA \\
\hline Halbach et al., 1998 & US & 8 & 5 & 2 & 2 & 3 & 0 & 0 & 0 & 0 & 0 \\
\hline lizuka et al., 1998 & Japan & 3 & NA & NA & NA & NA & NA & NA & NA & NA & NA \\
\hline Borthne et al., 1997 & Norway & 14 & NA & NA & NA & NA & NA & NA & NA & NA & NA \\
\hline Lasjaunias et al., 1995 & France & 52 & NA & NA & NA & NA & NA & NA & NA & NA & NA \\
\hline Rodesch et al., 1994 & France & 12 & 5 & 1 & 2 & 4 & 0 & 1 & 3 & 0 & 1 \\
\hline Lylyk et al., 1993 & US & 28 & NA & NA & NA & NA & NA & NA & NA & NA & NA \\
\hline Friedman et al., 1993 & US & 11 & 3 & 1 & 0 & 7 & 1 & 2 & NA & 0 & 0 \\
\hline Lasjaunias et al., 1991 & Canada & 34 & NA & NA & NA & NA & NA & NA & NA & NA & NA \\
\hline Garcia-Monaco et al., 1991 & France & 22 & NA & NA & NA & NA & NA & NA & NA & NA & NA \\
\hline Casasco et al., 1991 & Argentina & 7 & 2 & 0 & 0 & 4 & 0 & 0 & 1 & 0 & 0 \\
\hline Ciricillo et al., 1990 & US & 8 & 1 & 0 & 0 & 3 & 1 & 2 & 4 & 1 & 1 \\
\hline Lasjaunias et al., 1989 & France & 15 & 5 & 2 & 1 & 6 & 0 & 1 & 4 & 0 & 0 \\
\hline Hanner et al., 1988 & US & 15 & NA & NA & NA & NA & NA & NA & NA & NA & NA \\
\hline Burrows et al., 1987 & Canada & 3 & 1 & 0 & 0 & 2 & 2 & 1 & 0 & 0 & 0 \\
\hline
\end{tabular}

$\mathrm{CH}=$ cerebral hemorrhage; $\mathrm{VT}=$ venous thrombosis.

mortality, there was significant statistical heterogeneity for overall mortality rate $\left(\mathrm{p}<0.0001, \mathrm{I}^{2}=59.9 \%\right)$ and mortality for the nonembolized patients $\left(\mathrm{p}<0.0001, \mathrm{I}^{2}=90.7 \%\right)$; however, there was not significant statistical heterogeneity for mortality for embolized patients $\left(\mathrm{p}=0.005, \mathrm{I}^{2}=\right.$ $42.8 \%)$, technical mortality $\left(\mathrm{p}=0.9163, \mathrm{I}^{2}=0 \%\right)$, and other reasons $\left(\mathrm{p}=0.0306, \mathrm{I}^{2}=33.7 \%\right)$. There was also significant heterogeneity for postembolization complications $(\mathrm{p}$ $\left.<0.0001, \mathrm{I}^{2}=79.1 \%\right)$ : cerebral ischemia $\left(\mathrm{p}<0.0001, \mathrm{I}^{2}=\right.$ $60.8 \%)$ and developmental delay $\left(\mathrm{p}<0.0001, \mathrm{I}^{2}=64.2 \%\right)$, with the exception of cerebral hemorrhage $\left(\mathrm{p}=0.2062, \mathrm{I}^{2}\right.$ $=16.4 \%)$, hydrocephalus $\left(\mathrm{p}=0.0014, \mathrm{I}^{2}=47.7 \%\right)$, leg ischemia $\left(\mathrm{p}=0.8258, \mathrm{I}^{2}=0 \%\right)$, and vessel perforation $(\mathrm{p}=$ $\left.0.5393, \mathrm{I}^{2}=0 \%\right)$.
TABLE 5. Number of sessions and postembolization complications for patients who underwent endovascular therapy

\begin{tabular}{ccrr}
\hline & & \multicolumn{2}{c}{$\begin{array}{c}\text { Postembolization } \\
\text { Complications }\end{array}$} \\
\cline { 3 - 4 } No. of Sessions & Total No. of Patients & \multicolumn{1}{c}{$\mathrm{CH}^{*}$} & \multicolumn{1}{c}{ VT } \\
\hline 1 & 56 & $18(32 \%)$ & $15(27 \%)$ \\
\hline $2-3$ & 75 & $16(21 \%)$ & $18(24 \%)$ \\
\hline$>3$ & 33 & $6(18 \%)$ & $8(24 \%)$ \\
\hline Total & 164 & $40(24 \%)$ & $41(25 \%)$ \\
\hline
\end{tabular}

* Cerebral hemorrhage includes parenchymal bleeding, intraventricular hemorrhage, and subarachnoid hemorrhage. 


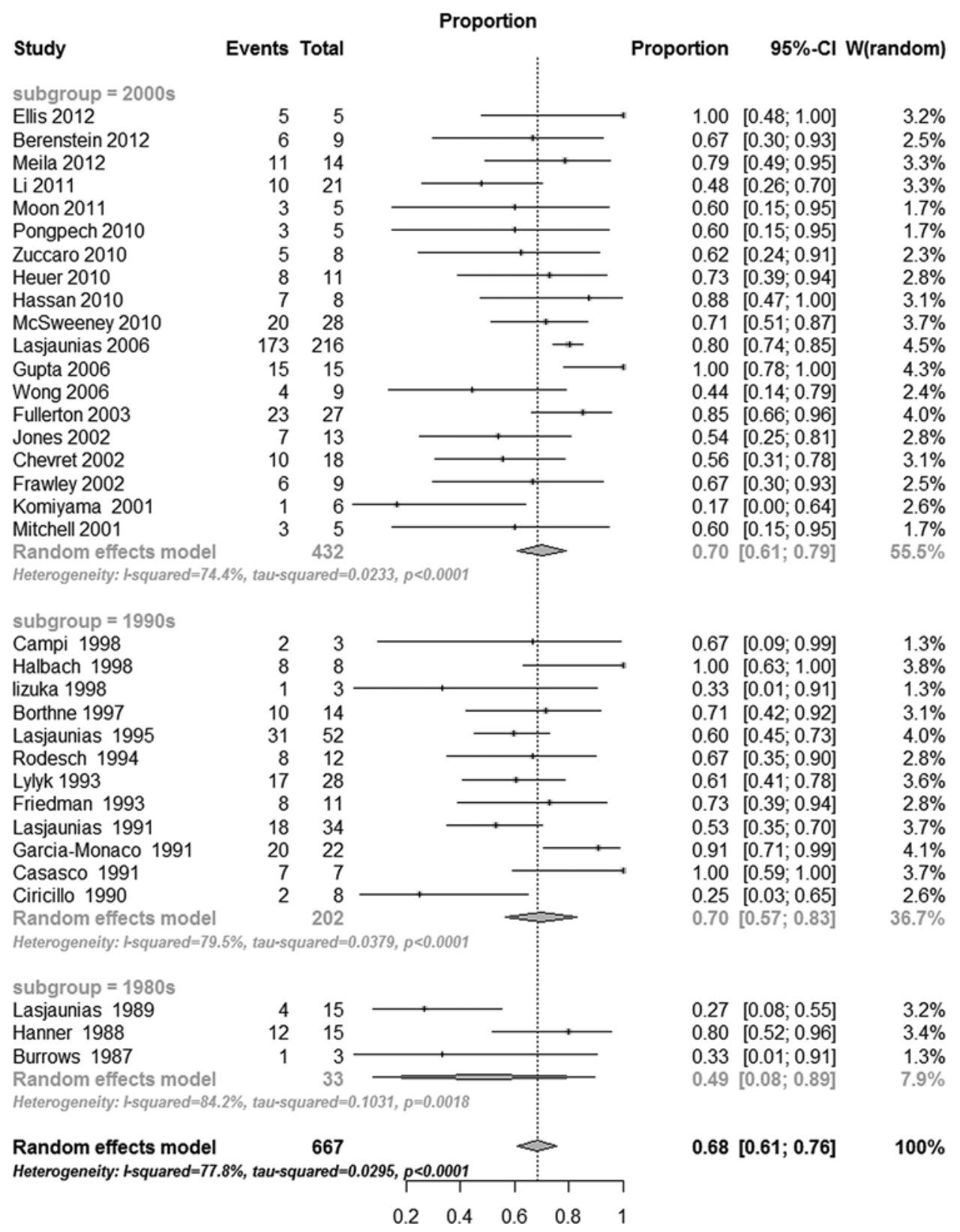

FIG. 2. Estimates of the proportion of the good outcome, including the $95 \% \mathrm{Cl}$ from the random-effects model and the number of patients for each study. $\mathrm{W}=$ weighted.

Statistical heterogeneity suggests that there might be differences in the effects of endovascular treatment for VGAMs across settings and populations, and we conducted prespecified subgroup analyses for all analyses according to race, the period, and the quality of profile. Trials were conducted in 13 countries. As described above (Fig. 8), endovascular treatment for VGAMs was associated with significant reductions in mortality, complications, and clinical outcome in both Asia and Africa. Trials were also conducted over the 1980s, 1990s, and 2000s. Endovascular treatment for VGAMs was associated with significant reductions in mortality, complications, and clinical outcome in both the 1990s and 2000s, while the difference between subgroups for the outcome was not significant. A nonrepresentative subset of studies reported data by quality of profile (Fig. 9), but these comparisons cannot be interpreted meaningfully.

\section{Publication Bias}

Begg's test and Egger's test showed no evidence of publication bias in some variables evaluated, such as age at treatment (infant, child, or adult), treatment result, mortality for the nonembolized patients, and complications (leg ischemia, vessel perforation) $(p>0.05)$. However, publication bias was identified in the following areas: age at treatment (neonate), clinical outcome, mortality (total 


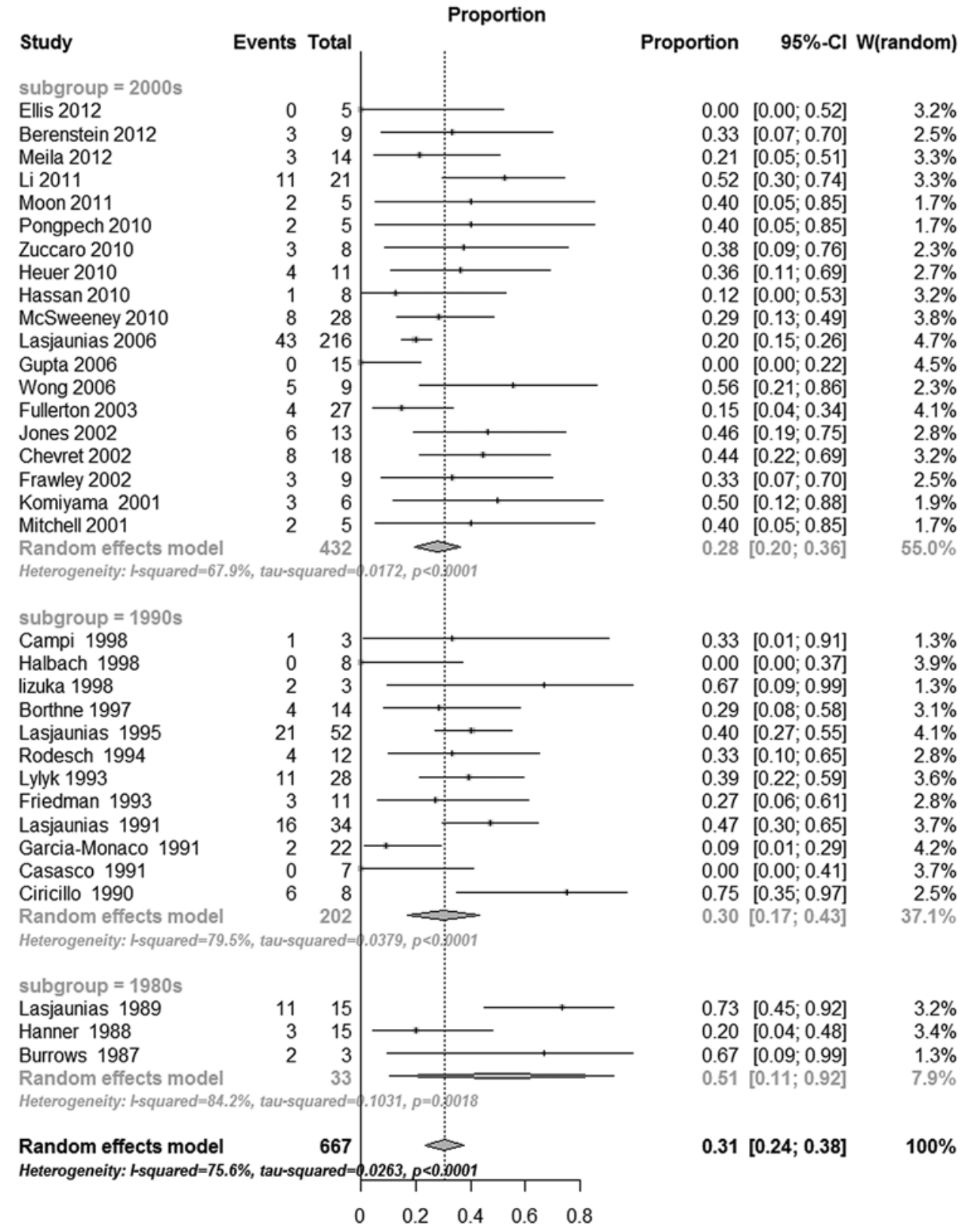

FIG. 3. Estimates of the proportion of the poor outcome, including the $95 \% \mathrm{Cl}$ from the random-effects model and the number of patients for each study.

mortality, mortality for the embolized patients, technical mortality, other reasons), and complications (cerebral hemorrhage, cerebral ischemia, hydrocephalus, and developmental delay) $(\mathrm{p}<0.05)$.

\section{Discussion}

Vein of Galen aneurysmal malformations are arteriovenous malformations of the choroidal system that develop in the early embryonic stage. ${ }^{1}$ They represent $30 \%$ of vascular malformations in the pediatric age group.

Routine prenatal ultrasound screening has become more and more common. All patients in this review were evaluated with imaging studies, such as MRI and CT. The diagnosis can be confirmed by vascular studies, such as MR angiography, CT angiography, or DSA. However, the therapeutic method was classified into 4 groups, including endovascular therapy, microsurgery (craniotomy and clip occlusion of the vessel), Gamma Knife surgery, and conservative management. As is well known, endovascular treatment has long been accepted as the first option for the treatment VGAMs. ${ }^{15,20,30,36,49}$ High mortality and morbidity of microsurgery, exceeding $90 \%$ in some studies, has led to the development of endovascular techniques that more effectively and safely treat VGAMs. ${ }^{2,26,29,43}$ However, Gamma Knife surgery achieved favorable outcomes in $88.9 \%$ of cases for long-term effects, as reported by Payne 


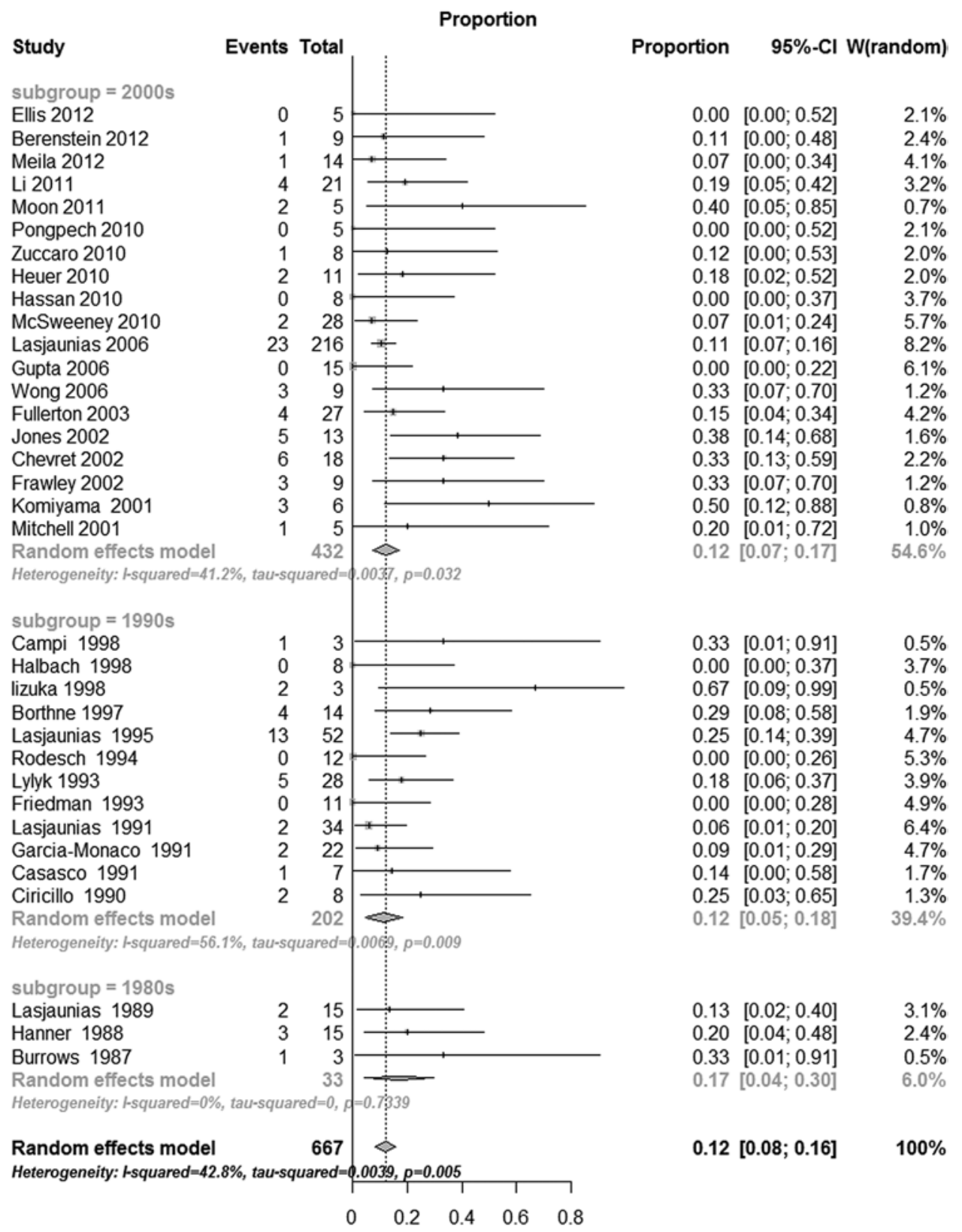

FIG. 4. Estimates of the postembolization mortality rate, including the $95 \% \mathrm{Cl}$ from the fixed-effects model and the number of patients for each study.

et al. ${ }^{44}$ Finally, patients who refused both endovascular and microsurgical treatment, choosing conservative medical management, had a high mortality rate.

Endovascular embolization has been more and more widely applied in clinics in recent years. ${ }^{3,12,40}$ The results suggest that advances in endovascular treatment have greatly improved the outcome of patients with VGAMs. However, what is the outcome for endovascular treatment? What are complication rates for VGAMs? No studies have looked at this aspect of the systematic evaluation before. The purpose of our study was to assess the outcome and complications of endovascular embolization to gain a better understanding of endovascular management.

\section{Age at Treatment}

When assessing the efficacy of endovascular embolization, the surgeon must often consider the age factor. Age is the main determinant of mortality risk. Accordingly, our study looks at the constituent ratio of patient age groups after endovascular embolization. In fact, it is a simple matter of constituent ratio. To some extent, the constituent ratio marks the distribution of age for the best treatment period and the prelude for the outcome of disease with embolization intervention, when compared with $100 \%$ natural history mortality rate of VGAMs. ${ }^{19}$ On the other hand, constituent ratios of each age group have been affected by different factors or initial presentations, 
TABLE 6. Causes of mortality in patients who underwent embolization

\begin{tabular}{|c|c|c|c|c|c|c|c|c|c|c|c|c|c|c|c|}
\hline \multirow[b]{2}{*}{ Authors \& Year } & \multirow[b]{2}{*}{ Country } & \multicolumn{5}{|c|}{ Technical Reasons } & \multicolumn{9}{|c|}{ Other (comorbidities) } \\
\hline & & Total & $\mathrm{CH}$ & $\mathrm{BC}$ & $\mathrm{CP}$ & $\mathrm{ICHF}^{*}$ & Total & PHF & $\mathrm{SDH}$ & $\mathrm{PI}$ & PND & RT & MBS & SS & MOF \\
\hline Ellis et al., 2012 & US & 0 & 0 & 0 & 0 & 0 & 0 & 0 & 0 & 0 & 0 & 0 & 0 & 0 & 0 \\
\hline Berenstein et al., 2012 & US & 1 & 1 & 0 & 0 & 0 & 0 & 0 & 0 & 0 & 0 & 0 & 0 & 0 & 0 \\
\hline Meila et al., 2012 & Germany & 0 & 0 & 0 & 0 & 0 & 1 & NA & NA & NA & NA & NA & NA & NA & NA \\
\hline Li et al., 2011 & Canada & 0 & 0 & 0 & 0 & 0 & 6 & 4 & 0 & 0 & 2 & 0 & 0 & 0 & 0 \\
\hline Moon et al., 2011 & Korea & 2 & 2 & 0 & 0 & 0 & 0 & 0 & 0 & 0 & 0 & 0 & 0 & 0 & 0 \\
\hline Pongpech et al., 2010 & Thailand & 0 & NA & NA & NA & NA & 0 & 0 & 0 & 0 & 0 & 0 & 0 & 0 & 0 \\
\hline Zuccaro et al., 2010 & Argentina & 0 & 0 & 0 & 0 & 0 & 1 & 1 & 0 & 0 & 0 & 0 & 0 & 0 & 0 \\
\hline Heuer et al., 2010 & US & 1 & 1 & 0 & 0 & 0 & 1 & 1 & 0 & 0 & 0 & 0 & 0 & 0 & 0 \\
\hline Hassan et al., 2010 & Egypt & 0 & 0 & 0 & 0 & 0 & 0 & 0 & 0 & 0 & 0 & 0 & 0 & 0 & 0 \\
\hline McSweeney et al., 2010 & England & 1 & 1 & 0 & 0 & 0 & 1 & 0 & 0 & 0 & 0 & 0 & 0 & 0 & 1 \\
\hline Lasjaunias et al., 2006 & France & 3 & NA & NA & NA & NA & 20 & NA & NA & NA & NA & NA & NA & NA & NA \\
\hline Gupta et al., 2006 & India & 0 & 0 & 0 & 0 & 0 & 0 & 0 & 0 & 0 & 0 & 0 & 0 & 0 & 0 \\
\hline Wong et al., 2006 & Australia & 1 & NA & NA & NA & NA & 2 & 0 & 0 & 0 & 2 & 0 & 0 & 0 & 0 \\
\hline Fullerton et al., 2003 & US & 0 & & 0 & 0 & 0 & 4 & 4 & 0 & 0 & 0 & 0 & 0 & 0 & 0 \\
\hline Jones et al., 2002 & US & 1 & 1 & 0 & 0 & 0 & 4 & 0 & 0 & 0 & 1 & 0 & 0 & 0 & 3 \\
\hline Chevret et al., 2002 & France & 0 & 0 & 0 & 0 & 0 & 6 & 6 & 0 & 0 & 0 & 0 & 0 & 0 & 0 \\
\hline Frawley et al., 2002 & Australia & 0 & 0 & 0 & 0 & 0 & 3 & 1 & 0 & 0 & 0 & 0 & 2 & 0 & 0 \\
\hline Komiyama et al., 2001 & Japan & 1 & 0 & 0 & 1 & 0 & 2 & 1 & 1 & 0 & 0 & 0 & 0 & 0 & 0 \\
\hline Mitchell et al., 2001 & Australia & 1 & 0 & 0 & 0 & 1 & 1 & 0 & 0 & 0 & 0 & 0 & 0 & 1 & 0 \\
\hline Campi et al., 1998 & France & 1 & 1 & 0 & 0 & 0 & 0 & 0 & 0 & 0 & 0 & 0 & 0 & 0 & 0 \\
\hline Halbach et al., 1998 & US & 0 & 0 & 0 & 0 & 0 & 0 & 0 & 0 & 0 & 0 & 0 & 0 & 0 & 0 \\
\hline lizuka et al., 1998 & Japan & 0 & 0 & 0 & 0 & 0 & 2 & 0 & 0 & 0 & 0 & 0 & 2 & 0 & 0 \\
\hline Borthne et al., 1997 & Norway & 1 & 1 & 0 & 0 & 0 & 3 & 2 & 0 & 1 & 0 & 0 & 0 & 0 & 0 \\
\hline Lasjaunias et al., 1995 & France & 2 & 2 & 0 & 0 & 0 & 1 & 0 & 0 & 0 & 0 & 1 & 0 & 0 & 0 \\
\hline Rodesch et al., 1994 & France & 0 & 0 & 0 & 0 & 0 & 0 & 0 & 0 & 0 & 0 & 0 & 0 & 0 & 0 \\
\hline Lylyk et al., 1993 & US & 5 & 0 & 0 & 2 & 1 & 2 & 1 & 0 & 0 & 1 & 0 & 0 & 0 & 0 \\
\hline Friedman et al., 1993 & US & 0 & 0 & 0 & 0 & 0 & 0 & 0 & 0 & 0 & 0 & 0 & 0 & 0 & 0 \\
\hline Lasjaunias et al., 1991 & Canada & 1 & 1 & 0 & 0 & 0 & 1 & 0 & 1 & 0 & 0 & 0 & 0 & 0 & 0 \\
\hline Garcia-Monaco et al., 1991 & France & 2 & 2 & 0 & 0 & 0 & 0 & 0 & 0 & 0 & 0 & 0 & 0 & 0 & 0 \\
\hline Casasco et al., 1991 & Argentina & 1 & 0 & 0 & 1 & 0 & 0 & 0 & 0 & 0 & 0 & 0 & 0 & 0 & 0 \\
\hline Ciricillo et al., 1990 & US & 1 & 0 & 1 & 0 & 0 & 1 & 0 & 0 & 1 & 0 & 0 & 0 & 0 & 0 \\
\hline Lasjaunias et al., 1989 & France & 0 & 0 & 0 & 0 & 0 & 2 & 0 & 2 & 0 & 0 & 0 & 0 & 0 & 0 \\
\hline Hanner et al., 1988 & US & 1 & 1 & 0 & 0 & 0 & 2 & 2 & 0 & 0 & 0 & 0 & 0 & 0 & 0 \\
\hline Burrows et al., 1987 & Canada & 1 & 1 & 0 & 0 & 0 & 0 & 0 & 0 & 0 & 0 & 0 & 0 & 0 & 0 \\
\hline
\end{tabular}

$\mathrm{BC}=$ broken catheter; $\mathrm{CH}=$ cerebral hemorrhage; $\mathrm{CP}=$ catheter perforation; $\mathrm{ICHF}=$ intractable congestive heart failure; $\mathrm{MBS}=$ melting brain syndrome; $\mathrm{MOF}=$ multiple organ failure; $\mathrm{PHF}=$ persistent heart failure; $\mathrm{PI}$ = pulmonary infarct; $\mathrm{PND}=$ progressive neurological deterioration; $\mathrm{RT}=$ rejected treatment; $\mathrm{SDH}=$ subdural hematoma; $S S=$ severe seizures.

* Due to failed embolization.

reflecting the characteristics of the diseases at different stages.

First, the result of our constituent ratio shows that the neonate group accounts for the highest percentage of cases at $44 \%$ (95\% CI $31 \%-57 \%)$. As congestive heart failure cannot be controlled effectively with medical treatment, most patients cannot wait until they are 5 or 6 months of age when emergency embolization is suggested. ${ }^{36} \mathrm{Se}-$ vere cardiorespiratory alterations are the most significant symptoms associated with neonatal diagnosis. Cardiovascular and respiratory distress syndromes result from the high-flow arteriovenous shunts of VGAM. ${ }^{16}$ Indeed, highoutput cardiac failure was presented in 94\% of VGAM cases in the neonatal period, as reported by Rodesch et al. ${ }^{46}$ Roughly, the higher the constituent ratio of neonate group with embolization, the greater the proportion of emergency treatments.

The next age group, the infant group, accounts for $41 \%$ (95\% CI 30\%-51\%). Whereas congestive heart failure can be managed with medical treatment or is not present, endovascular embolization should be deferred until the best time for the operation. Smaller shunts and milder cardiac 


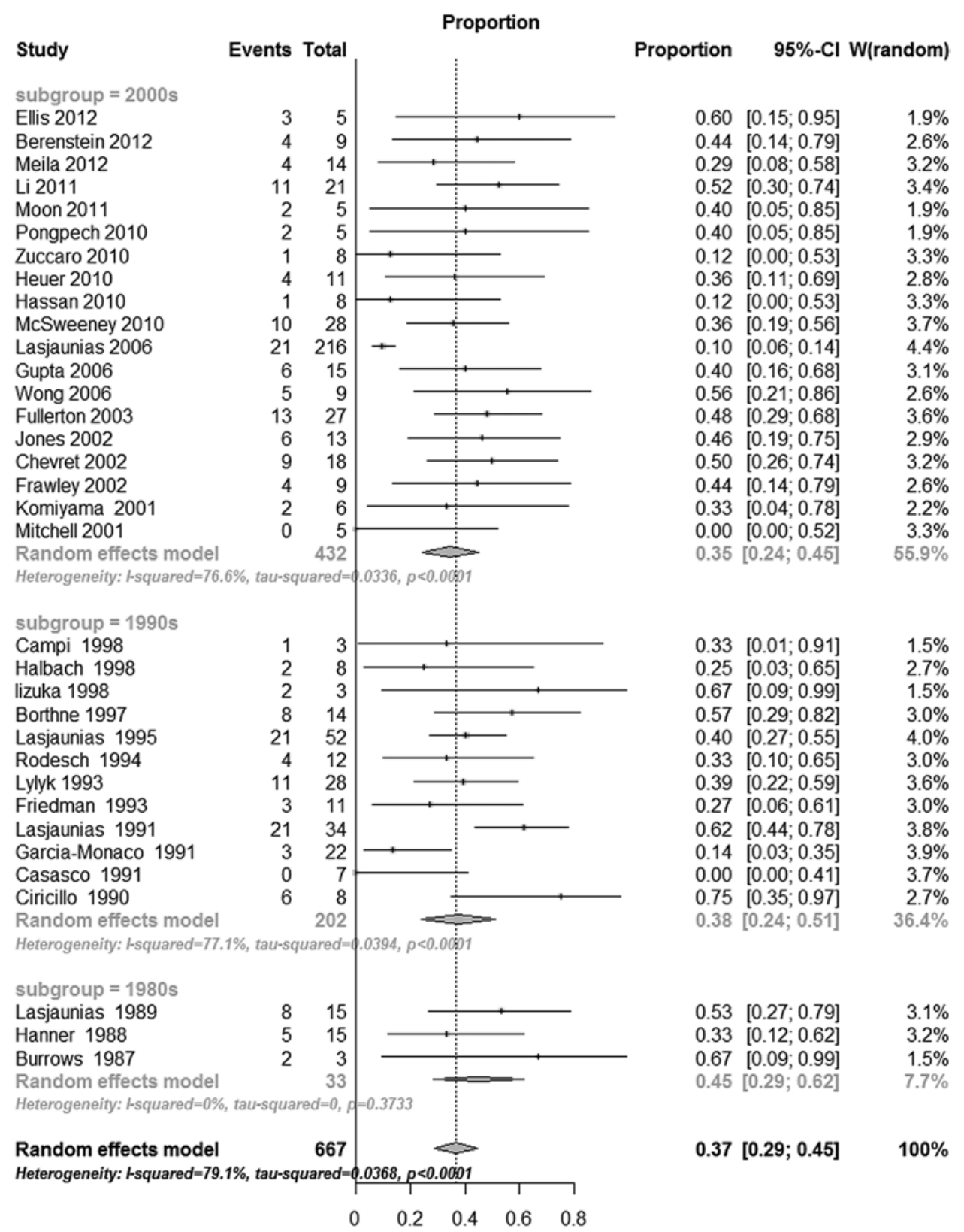

FIG. 5. Estimates of the rate of postembolization complications, including the $95 \% \mathrm{Cl}$ from the random-effects model and the number of patients for each study.

symptoms are the most common symptoms for infants. Hydrocephalus is the most important symptom associated with a diagnosis of VGAM during infancy. Communicating hydrocephalus is considered to be a result of an impaired CSF resorption function of arachnoid granulations by subarachnoid blood, whereas noncommunicating hydrocephalus results from a venous aneurysm oppressing the corpora quadrigemina or aqueduct, leading to blockage of cerebrospinal fluid circulation. ${ }^{16}$ Other clinical presentations associated with diagnosis during infancy were seizures and increased head circumference. The clinical symptoms of this period often did not need immediate treatment. So, to some extent, the rate of elective emboli- zation procedures was reflected by the constituent ratio of infant group.

Finally, the group with children and adults accounts for the lowest percentage at $12 \%$ (95\% CI 7\%-16\%). The symptoms of this group are often milder. Headaches and subarachnoid hemorrhage are the most typical symptoms for children. In these cases, lesions are generally small and the arteriovenous shunts have low velocity. Adults are rarely diagnosed with VGAM, accounting for the low constituent ratio in children and adults who have undergone embolization, but diagnosis in this group is becoming more common as imaging techniques are improving. ${ }^{16}$ This shows that our understanding of VGAMs is still pro- 
TABLE 7. Main outcome criteria (mortality, good/poor clinical outcome, complications) over the 1980s, 1990s, and $2000 \mathrm{~s}$

\begin{tabular}{ccccc}
\hline & & & \multicolumn{2}{c}{ Clinical Outcome } \\
\cline { 3 - 5 } Decade & Mortality of Embolized Patients & Complications & Good & Poor \\
\hline $1980 \mathrm{~s}$ & $17 \%(4-30 \%)$ & $45 \%(29-62 \%)$ & $49 \%(8-89 \%)$ & $51 \%(11-92 \%)$ \\
\hline $1990 \mathrm{~s}$ & $12 \%(5-18 \%)$ & $38 \%(24-52 \%)$ & $70 \%(57-83 \%)$ & $30 \%(17-43 \%)$ \\
\hline $2000 \mathrm{~s}$ & $12 \%(7-17 \%)$ & $35 \%(24-45 \%)$ & $70 \%(61-79 \%)$ & $28 \%(20-36 \%)$ \\
\hline
\end{tabular}

gressing. Lesions producing mild symptoms or asymptomatic lesions are not dangerous.

The distribution of constituent ratio of the age groups reflected the choice of timing for endovascular treatment. Lasjaunias et al. ${ }^{36}$ recommended that the timing of endovascular treatment should be determined by the clinical presentation of the patient. Treatment should be delayed until the patient is 5 or 6 months of age, because it presents little risk to normal brain maturation and maximizes the efficacy of treatment. ${ }^{21}$ As soon as the cardiovascular or neurological symptoms cannot be managed medically, emergency embolization should be performed.

\section{Treatment Results}

Complete occlusion and partial occlusion were performed in 57\% (95\% CI 48\%-65\%) and 43\% (95\% CI $34 \%-51 \%$ ) of cases, respectively; the proportion was almost 50\%/50\%. Endovascular embolization can occlude the lesion entirely; however, complete occlusion performed in a single session is extremely dangerous. Some authors believe that the advantage of partial occlusion lies in reducing the risk of congestive heart failure in neonates, and, in some centers, the outcome of partial occlusion may be superior to that of complete occlusion. ${ }^{9}$ Partial occlusion may itself promote thrombosis in lesions and avoid the later procedures. In fact, staged embolization has been carried out in many patients with larger lesions. The above opinions are consistent with our statistical results. Here the goal is not complete occlusion of the lesion, but rather partial obliteration, to redistribute blood flow to allow for normal cardiac and neurological development. ${ }^{20}$ As a result, with very similar statistical re- sults, we can draw the conclusion that a decision whether to adopt the method of complete occlusion depends not only on the type of lesion, the amount of blood supplying arteries and venous drainage, but also, and more importantly, on the experience of the surgeon. From the perspective of the long-term results, however, we must clarify that the ultimate goal of treatment after the conclusion of the staged procedures was complete occlusion to avoid recruitment and expansion with time. The purpose of the partial occlusion is only to gain time and to control the acute situation.

\section{Clinical Outcome}

Clinical outcome is one of the important indicators of effective embolization therapy. In our study, of the 667 patients who underwent endovascular embolization between 1987 and 2014, 68\% had a good outcome and 31\% had a poor outcome, including $10 \%$ who died. In the literature review by Khullar et al., ${ }^{31}$ of the 337 patients who underwent endovascular embolization between 2001 and 2010, $60.8 \%$ had a good outcome, $39.1 \%$ had a poor outcome, and $15.7 \%$ died. Comparing these 2 studies, the poor outcome and mortality rates were lower in the former study than the latter. The reason for the difference is due to different inclusion criteria and the number of case studies analyzed. In other words, our research had looser inclusion criteria and included more case studies.

The good/poor clinical outcome was not only related to embolization technology, but also to a number of other factors, such as poor clinical presentation with multiorgan failure, the presence of neurological deficit, CT or MRI findings of parenchymal calcifications and extensive en-

Random sequence generation (selection bias)

Allocation concealment (selection bias)

Blinding of participants and personnel (performance bias)

Blinding of outcome assessment (detection bias)

Incomplete outcome data (attrition bias)

Selective reporting (reporting bias)

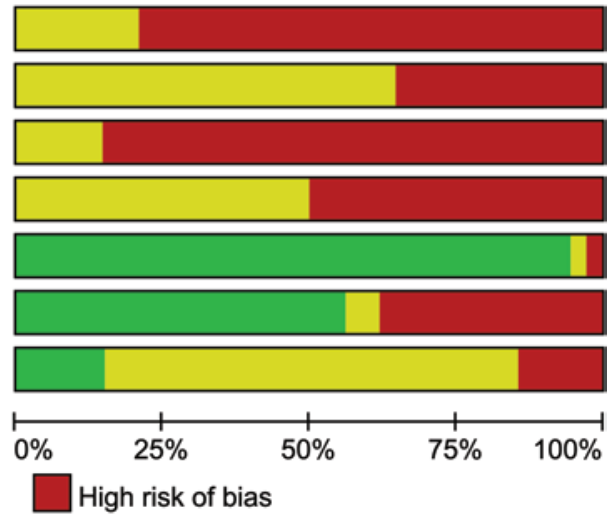

Low risk of bias

Unclear risk of bias

Other bias

FIG. 6. Risk of bias graph. Review of our judgment about each risk of bias item presented as percentages across all included studies. Figure is available in color online only. 


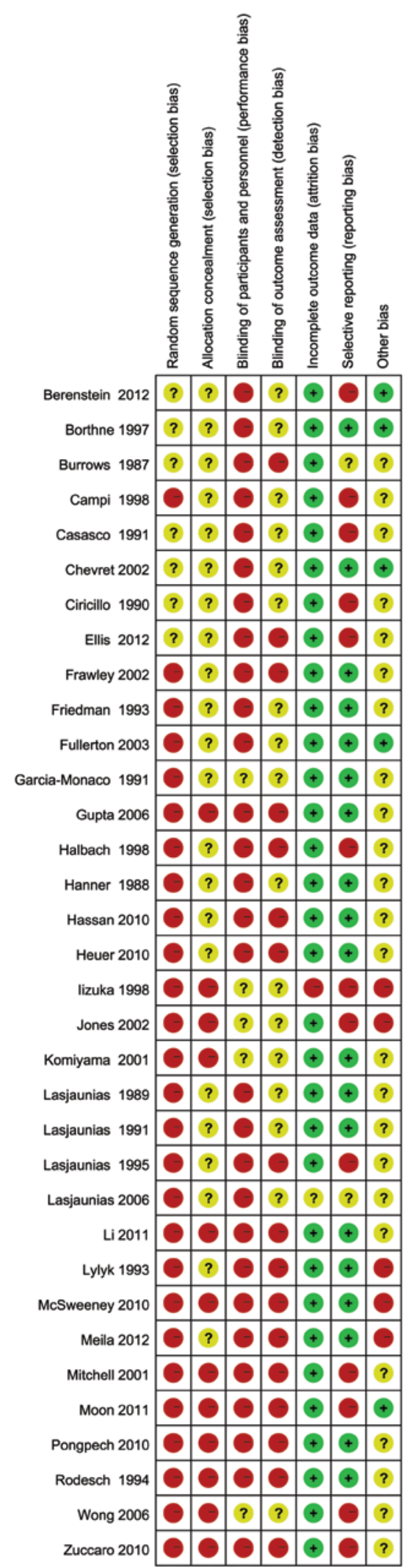

FIG. 7. Assessment of risk of bias in studies on effect of prognosis and postembolization complications after endovascular embolization for vein of Galen malformations. Red circles (-) indicate a high risk of bias, yellow circles (?) indicate an unclear risk of bias, and green circles $(+)$ indicate a low risk of bias. Figure is available in color online only. cephalomalacic parenchymal changes, DSA findings of arterial steal, and evidence of high-flow multifeeder shunts..$^{18}$ Emergency embolization should be performed in patients with severe congestive heart failure, progressive occlusion of the venous outflow, and the existence of artery steal, but not if there is evidence of permanent brain damage on MRI or CT scans. In a word, in deciding how to treat a VGAM patient, we should consider all the above factors to improve the outcome for patients.

\section{Mortality}

The overall mortality rate in this study was $16 \%$. Mortality for embolized patients (10\%) was lower than that for nonembolized patients (47\%). However, the nonembolized patient group included patients who did not receive endovascular embolization, but could have received other treatments such as microsurgery, Gamma Knife surgery, or medical management. Therefore, to some extent, we can draw a conclusion that endovascular embolization is the first treatment option for VGAMs in comparison with microsurgery, Gamma Knife surgery, or medical management. This result is in accord with the conclusion of Khullar and colleagues' study. ${ }^{31}$ We further analyzed the causes of death in embolized patients. Mortality related to embolization process techniques $(2 \%)$ was lower than mortality due to other causes or comorbidities (6\%). To some extent, the results proved the safety of embolization. On further analysis, the technical complications, in order of high to low incidence, were cerebral hemorrhage, intractable congestive heart failure due to failed embolization, broken catheter, and catheter perforation.

\section{Complications}

\section{Cerebral Hemorrhage and Cerebral Ischemia}

The rates of postembolization complications are described in Results. From the results shown, we can draw the following conclusion. If we completely occlude the fistula or occlude most fistulas at one time, the chances of complications with cerebral hemorrhage and cerebral ischemia are higher. The key aim of endovascular therapy of VGAM is to occlude the arteriovenous fistula and try to avoid damaging the venous drainage system. ${ }^{27}$ Given the deep lesion site, complex structure, and difficult surgery, such factors are likely to cause cerebral hemorrhage, even leading to death. This is due to a sudden reversal of blood steal resulting in excessive blood perfusion syndrome. After occluding the main blood artery supply of the VGAM, the internal pressure of lesions and blood flow velocity are significantly lower. The blood in the lesions is blocked, leading to thrombosis. Blood clots are extended to the collateral venous circulation, which connects with the VGAM. These veins are often the most important routes of normal brain tissue drainage. Extended blood clots can cause adverse consequences. ${ }^{11}$

The results of our study prove the existence of a relationship between the number of processes and the extent of postembolization complications. It is ideal to achieve complete occlusion of the lesion in the fewest number of sessions possible, but endovascular embolization often requires multiple sessions. The number of sessions is deter- 


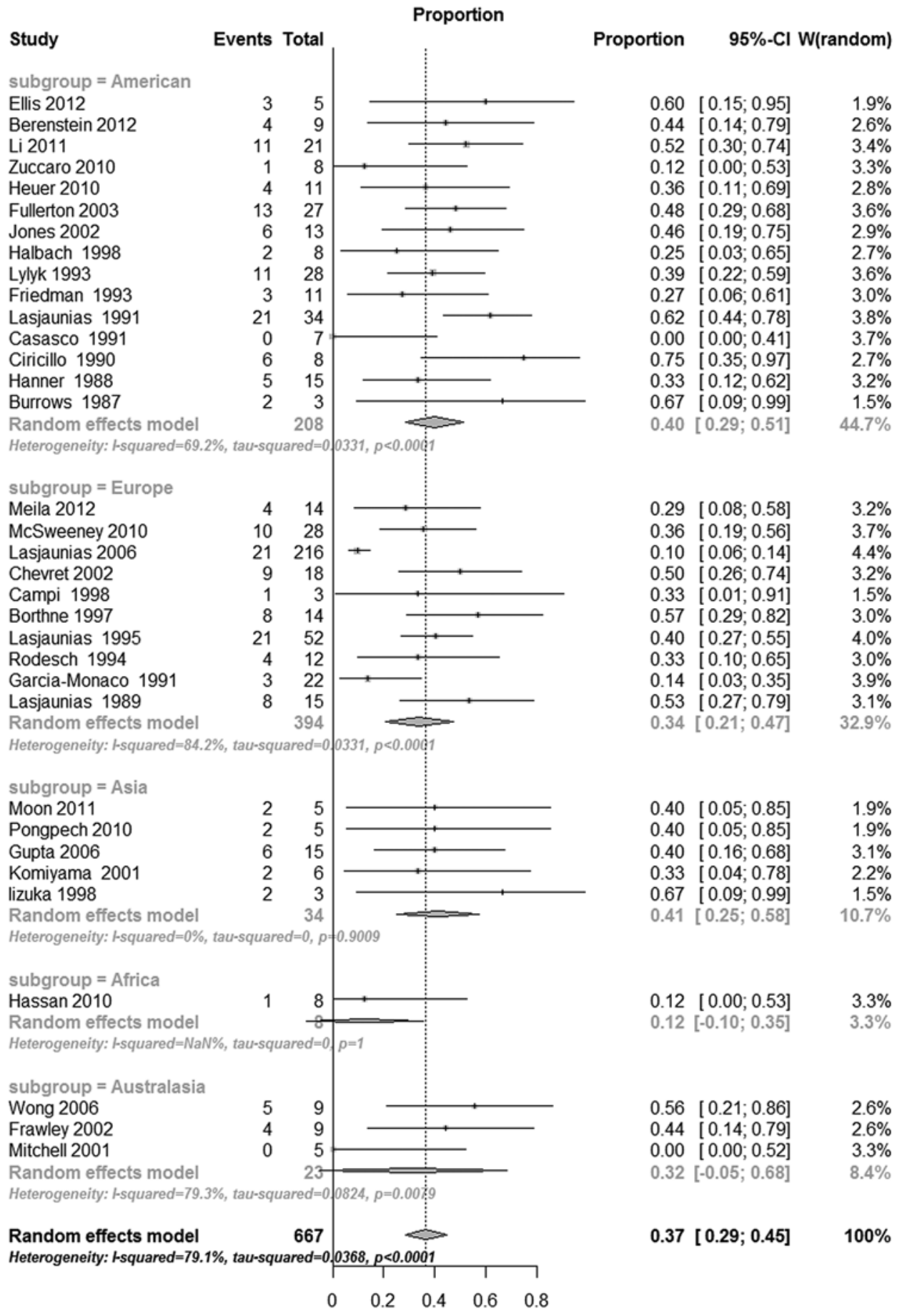

FIG. 8. The subgroup analyses for rate of postembolization complications according to race, including the $95 \% \mathrm{Cl}$ from the random-effects model and the number of patients for each study.

mined by the angioarchitecture of the lesion and the clinical presentation of the patient. Endovascular embolization is usually performed at 3- to 6-month intervals. ${ }^{36}$ Intracerebral hemorrhage and venous thrombosis can be largely avoided by staging the embolization procedure. ${ }^{16}$

\section{Hydrocephalus and Developmental Delay}

As a matter of fact, hydrocephalus and developmental delay are not in themselves complications of embolization treatments for VGAM, but both frequently impact on the outcome of VGAM patients. The pathological mechanism is as follows. The vein of Galen extends to the size of a tennis ball, oppressing the corpora quadrigemina and aqueduct. This leads to the blockage of cerebrospinal fluid circulation, namely hydrocephalus; a blood steal then triggers cerebral ischemia and encephalatrophy, eventually leading 


\begin{tabular}{|c|c|c|c|c|c|c|c|}
\hline & & & & roportion & & & \\
\hline Study & Events & Total & & & Proportion & $95 \%-\mathrm{Cl}$ & random) \\
\hline subgroup $=$ moderate & & & & & & & \\
\hline Ellis 2012 & 3 & 5 & & & 0.60 & {$[0.15 ; 0.95]$} & $1.9 \%$ \\
\hline Berenstein 2012 & 4 & 9 & & & 0.44 & {$[0.14 ; 0.79]$} & $2.6 \%$ \\
\hline Fullerton 2003 & 13 & 27 & & & 0.48 & {$[0.29 ; 0.68]$} & $3.6 \%$ \\
\hline Chevret 2002 & 9 & 18 & & & 0.50 & {$[0.26 ; 0.74]$} & $3.2 \%$ \\
\hline Frawley 2002 & 4 & 9 & & & 0.44 & {$[0.14 ; 0.79]$} & $2.6 \%$ \\
\hline Komiyama 2001 & 2 & 6 & & & 0.33 & {$[0.04 ; 0.78]$} & $2.2 \%$ \\
\hline Borthne 1997 & 8 & 14 & & & 0.57 & {$[0.29 ; 0.82]$} & $3.0 \%$ \\
\hline Friedman 1993 & 3 & 11 & & & 0.27 & {$[0.06 ; 0.61]$} & $3.0 \%$ \\
\hline Lasjaunias 1991 & 21 & 34 & & & 0.62 & {$[0.44 ; 0.78]$} & $3.8 \%$ \\
\hline Garcia-Monaco 1991 & 3 & 22 & & & 0.14 & {$[0.03 ; 0.35]$} & $3.9 \%$ \\
\hline Casasco 1991 & 0 & 7 & & 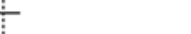 & 0.00 & {$[0.00 ; 0.41]$} & $3.7 \%$ \\
\hline Ciricillo 1990 & 6 & 8 & & & 0.75 & {$[0.35 ; 0.97]$} & $2.7 \%$ \\
\hline Hanner 1988 & 5 & 15 & & & 0.33 & {$[0.12 ; 0.62]$} & $3.2 \%$ \\
\hline Burrows 1987 & 2 & 3 & & & 0.67 & {$[0.09 ; 0.99]$} & $1.5 \%$ \\
\hline Random effects model & & 188 & $\rightarrow$ & $x_{\infty}$ & 0.42 & {$[0.29 ; 0.55]$} & $40.9 \%$ \\
\hline Heterogeneity: 1 -squared $=75 \%$ & 6 , tau-squa & ared $=0$. & $436, p<0.000$ & & & & \\
\hline subgroup = very low & & & & & & & \\
\hline Meila 2012 & 4 & 14 & & & 0.29 & {$[0.08 ; 0.58]$} & $3.2 \%$ \\
\hline Li 2011 & 11 & 21 & & & 0.52 & {$[0.30 ; 0.74]$} & $3.4 \%$ \\
\hline Moon 2011 & 2 & 5 & & & 0.40 & {$[0.05 ; 0.85]$} & $1.9 \%$ \\
\hline Pongpech 2010 & 2 & 5 & & & 0.40 & {$[0.05 ; 0.85]$} & $1.9 \%$ \\
\hline Zuccaro 2010 & 1 & 8 & & & 0.12 & {$[0.00 ; 0.53]$} & $3.3 \%$ \\
\hline McSweeney 2010 & 10 & 28 & & & 0.36 & {$[0.19 ; 0.56]$} & $3.7 \%$ \\
\hline Mitchell 2001 & 0 & 5 & & & 0.00 & {$[0.00 ; 0.52]$} & $3.3 \%$ \\
\hline lizuka 1998 & 2 & 3 & & & 0.67 & {$[0.09 ; 0.99]$} & $1.5 \%$ \\
\hline Rodesch 1994 & 4 & 12 & & & 0.33 & {$[0.10 ; 0.65]$} & $3.0 \%$ \\
\hline Random effects model & & 101 & 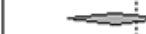 & - & 0.31 & {$[0.18 ; 0.44]$} & $25.1 \%$ \\
\hline Heterogeneity: 1 -squared $=50.7$ & $7 \%$, tau-squ & uared $=0$ & $.018, \rho=0.039 ?$ & & & & \\
\hline subgroup $=10 \mathrm{w}$ & & & & & & & \\
\hline Heuer 2010 & 4 & 11 & & & 0.36 & {$[0.11 ; 0.69]$} & $2.8 \%$ \\
\hline Hassan 2010 & 1 & 8 & & & 0.12 & {$[0.00 ; 0.53]$} & $3.3 \%$ \\
\hline Lasjaunias 2006 & 21 & 216 & + & & 0.10 & {$[0.06 ; 0.14]$} & $4.4 \%$ \\
\hline Gupta 2006 & 6 & 15 & & & 0.40 & {$[0.16 ; 0.68]$} & $3.1 \%$ \\
\hline Wong 2006 & 5 & 9 & & & 0.56 & {$[0.21 ; 0.86]$} & $2.6 \%$ \\
\hline Jones 2002 & 6 & 13 & & & 0.46 & {$[0.19 ; 0.75]$} & $2.9 \%$ \\
\hline Campi 1998 & 1 & 3 & & & 0.33 & {$[0.01 ; 0.91]$} & $1.5 \%$ \\
\hline Halbach 1998 & 2 & 8 & & & 0.25 & {$[0.03 ; 0.65]$} & $2.7 \%$ \\
\hline Lasjaunias 1995 & 21 & 52 & & & 0.40 & {$[0.27 ; 0.55]$} & $4.0 \%$ \\
\hline Lylyk 1993 & 11 & 28 & & & 0.39 & {$[0.22 ; 0.59]$} & $3.6 \%$ \\
\hline Lasjaunias 1989 & 8 & 15 & - & & 0.53 & {$[0.27 ; 0.79]$} & $3.1 \%$ \\
\hline Random effects model & & 378 & $\Rightarrow$ & $=-$ & 0.34 & {$[0.21 ; 0.48]$} & $34.0 \%$ \\
\hline Heterogeneity: 1 -squared $=81.5$ & $\%$, tau-squ & uared $=$ & $.0352, p<0.00$ & & & & \\
\hline Random effects model & & 667 & & & 0.37 & {$[0.29 ; 0.45]$} & $100 \%$ \\
\hline Heterogeneity: -squared $=79.1$ & 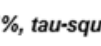 & . & $0.0368, \rho<0.0$ & & & & \\
\hline & & $\mathrm{c}$ & 0.2 & 08 & & & \\
\hline
\end{tabular}

FIG. 9. The subgroup analyses for rate of postembolization complications according to the quality of profile, including the $95 \% \mathrm{Cl}$ from the random-effects model and the number of patients for each study.

to developmental delay, mental retardation, or neurological deficit.

Geibprasert et al. ${ }^{18}$ believed that proper early management by decreasing the venous pressure through embolization of the high-flow shunt improves the chance for a better outcome in these patients. In these cases, early ventricular shunting is known to have a poor outcome. ${ }^{21}$ Therefore, ventricular drainage should be used only for those patients who do not improve after embolization or who have hydrocephalus unrelated to the VGAM. The same applies to patients with mental retardation.

\section{Leg Ischemia and Vessel Perforation}

In comparison with adults, leg ischemia and vessel perforation are characteristic complications for pediatric patients with femoral artery occlusion, due to repeated femoral artery puncture. We must be very careful in terms of compression and hemostasis after the procedure to prevent compromising the long-term patency of the vessels. Another technical complication of vessel perforation or microcatheter rupture can result in stroke and the permanent neurological deficit of mild hemiparesis where perforation of the feeding arteries occurred during the operation. Immediate embolization with $N$-butyl cyanoacrylate or Onyx should be performed. Perforation of the venous sac has been reported to occur during positioning of the microcatheter during coil embolization and can usually be managed by reversal of anticoagulation and continuation 
of coil embolization. Leg ischemia and vessel perforation belong to the category of technical complications. These complications can be avoided by surgical proficiency and careful manipulation. Potential complications include pulmonary embolization. Pulmonary embolization with embolic agents is common, considering the high flow across the intracranial shunt.

\section{Main Outcome Criteria (Mortality, Good/Poor Outcome, Complications) Over the 1980s, 1990s, and 2000s}

Our literature review extended over several decades. Most studies actually included in the analysis were from the 1980s, 1990s, and 2000s, a period of tremendous advancement in endovascular techniques. During time interval of 1980s, 1990s, and 2000s, the mortality rate of embolized patients declined from $17 \%$ to $12 \%$. The complication rate dropped from $45 \%$ to $35 \%$. The proportion of the poor outcome decreased from $51 \%$ to $28 \%$; moreover, the proportion of the good outcome increased from $49 \%$ to $70 \%$. The results suggest that advances in endovascular treatment have greatly improved the outcome of patients with VGAMs. With the development of science and technology, endovascular techniques have become more advanced, and thus are more beneficial to patients. Embolization treatment achieved so much progress that other methods such as microsurgery, Gamma Knife surgery, and medical management cannot be compared with endovascular treatment, especially in terms of the mortality rate. ${ }^{31}$

\section{Limitations}

Although our meta-analysis results are provocative, several limitations should be taken into consideration. Our review included a small number of subjects, mainly due to the paucity of studies that have directly compared endovascular embolization with other approaches. Nevertheless, our findings are in accordance with the results of an extensive literature search, in which we identified studies conducted on diverse patient populations around the world. Therefore, we believe our results are also relevant to other populations.

As in many retrospective analyses, the limitations of the study include the lack of randomization. The systematic review can be affected by the selection, investigation, and reporting biases in this area of clinical research. First, Egger's test showed evidence of publication bias existing in the following areas: clinical outcome, mortality (total mortality, MEP, technical mortality, other reasons), and complications (cerebral hemorrhage, cerebral ischemia, hydrocephalus, and developmental delay). This bias may have been due to the fact that unreported data were not included or the absence of reporting of side effects of endovascular embolization for VGAMs. The number of published studies included in our meta-analysis was not sufficiently large for a comprehensive analysis. Second, there was significant heterogeneity among the studies in terms of the different groups evaluated, which could have influenced the accuracy of our evaluation of endovascular embolization.

However, on the side of publication bias, using systematic reviews to find relevant studies to answer a question could be considered an unusual technique, but we do not think that this led us to "biased" results. All of the included systematic reviews used very comprehensive search strategies. By using Begg's test and Egger's test, we were able to quantify the publication bias effect sizes. Publication bias occurs when medical journals publish more studies favoring one intervention than studies favoring another one. Publication bias would be particularly frequent for studies with a small sample size. Second, on the other side, there is the quality of the evidence. Blinding was usually not used in these studies. For the endovascular embolization for VGAMs, blinding of participants is not feasible and blinding of study personnel is unrealistic, at least for the intraoperative and immediate postembolization periods. As stated above, publication bias exists in our studies, which resulted in degrading of the quality of the studies. However, our goal is to invite the trial authors to make a clear statement on the mortality and complications of the techniques that they were studying. Third, although we did not find evidence of specific contributors to heterogeneity in this review, we think that heterogeneity might be related to differences in the interventions and study design, details of which are routinely underreported in trials.

Thus, publication bias partially influenced the results of the meta-analysis. Subgroup analyses in this review were limited by the available data, which indicates that our results and their potential clinical application should be interpreted with caution. However, these limitations could be attributed to differences in patient outcome. Further analyses with individual patient data from large, multicenter, prospective, randomized controlled double-blind trials and observational studies would be more informative.

\section{Conclusions}

The successful treatment of VGAMs remains a complex therapeutic challenge. The results of our meta-analysis give a clear indication that endovascular treatment should be the first option for VGAMs. Our literature analysis suggests that vein of Galen malformations with endovascular embolization can result in acceptable the rate of mortality, complications, and good clinical outcome. Above all, the timing and course of endovascular treatment is dictated by the clinical presentation of the patient. This therapeutic window represents the optimal time for treatment. Intracerebral hemorrhage and venous thrombosis can be avoided, to a large extent, by staging the embolization procedure. The goal is not complete occlusion of the lesion, but rather partial obliteration to redistribute blood flow to allow for normal cardiac and neurological development. Future multicentered, randomized trials are necessary to confirm these findings as the number of studies included in this analysis was small in scale.

\section{Acknowledgments}

We thank Professor John Edward Shevland, MD, for his language editing, which substantially improved the quality of the manuscript.

\section{References}

1. Alvarez H, Garcia Monaco R, Rodesch G, Sachet M, Krings 
T, Lasjaunias P: Vein of Galen aneurysmal malformations. Neuroimaging Clin N Am 17:189-206, 2007

2. Amacher AL, Shillito J Jr: The syndromes and surgical treatment of aneurysms of the great vein of Galen. J Neurosurg 39:89-98, 1973

3. Berenstein A, Fifi JT, Niimi Y, Presti S, Ortiz R, Ghatan S, et al: Vein of Galen malformations in neonates: new management paradigms for improving outcomes. Neurosurgery 70:1207-1214, 2012

4. Borthne A, Carteret M, Baraton J, Courtel J, Brunelle F: Vein of Galen vascular malformations in infants: clinical, radiological and therapeutic aspect. Eur Radiol 7:1252-1258, 1997

5. Burrows PE, Lasjaunias PL, Ter Brugge KG, Flodmark O: Urgent and emergent embolization of lesions of the head and neck in children: indications and results. Pediatrics 80:386394, 1987

6. Campi A, Rodesch G, Scotti G, Lasjaunias P: Aneurysmal malformation of the vein of Galen in three patients: clinical and radiological follow-up. Neuroradiology 40:816-821, 1998

7. Casasco A, Lylyk P, Hodes JE, Kohan G, Aymard A, Merland JJ: Percutaneous transvenous catheterization and embolization of vein of Galen aneurysms. Neurosurgery 28:260-266, 1991

8. Chevret L, Durand P, Alvarez H, Lambert V, Caeymax L, Rodesch G, et al: Severe cardiac failure in newborns with VGAM. Prognosis significance of hemodynamic parameters in neonates presenting with severe heart failure owing to vein of Galen arteriovenous malformation. Intensive Care Med 28:1126-1130, 2002

9. Ciricillo SF, Edwards MS, Schmidt KG, Hieshima GB, Silverman NH, Higashida RT, et al: Interventional neuroradiological management of vein of Galen malformations in the neonate. Neurosurgery 27:22-28, 1990

10. Deeks JJ: Systematic reviews in health care: Systematic reviews of evaluations of diagnostic and screening tests. BMJ 323:157-162, 2001

11. Duckwiler GR, Dion JE, Viñuela F, Reichman A: Delayed venous occlusion following embolotherapy of vascular malformations in the brain. AJNR Am J Neuroradiol 13:15711579, 1992

12. Ellis JA, Orr L, Ii PC, Anderson RC, Feldstein NA, Meyers PM: Cognitive and functional status after vein of Galen aneurysmal malformation endovascular occlusion. World J Radiol 4:83-89, 2012

13. Frawley GP, Dargaville PA, Mitchell PJ, Tress BM, Loughnan $P$ : Clinical course and medical management of neonates with severe cardiac failure related to vein of Galen malformation. Arch Dis Child Fetal Neonatal Ed 87:F144-F149, 2002

14. Friedman DM, Verma R, Madrid M, Wisoff JH, Berenstein A: Recent improvement in outcome using transcatheter embolization techniques for neonatal aneurysmal malformations of the vein of Galen. Pediatrics 91:583-586, 1993

15. Fullerton HJ, Aminoff AR, Ferriero DM, Gupta N, Dowd CF: Neurodevelopmental outcome after endovascular treatment of vein of Galen malformations. Neurology 61:1386-1390, 2003

16. Gailloud P, O’Riordan DP, Burger I, Levrier O, Jallo G, Tamargo RJ, et al: Diagnosis and management of vein of Galen aneurysmal malformations. J Perinatol 25:542-551, 2005

17. Garcia-Monaco R, De Victor D, Mann C, Hannedouche A, terBrugge K, Lasjaunias P: Congestive cardiac manifestations from cerebrocranial arteriovenous shunts. Endovascular management in 30 children. Childs Nerv Syst 7:48-52, 1991

18. Geibprasert S, Krings T, Armstrong D, terBrugge KG, Raybaud CA: Predicting factors for the follow-up outcome and management decisions in vein of Galen aneurysmal malformations. Childs Nerv Syst 26:35-46, 2010
19. Gold A, Ransohoff J, Carter S: Vein of Galen malformation. Acta Neurol Scand Suppl 40 (Suppl 11):11-31, 1964

20. Gupta AK, Rao VR, Varma DR, Kapilamoorthy TR, Kesavadas C, Krishnamoorthy T, et al: Evaluation, management, and long-term follow up of vein of Galen malformations. J Neurosurg 105:26-33, 2006

21. Gupta AK, Varma DR: Vein of Galen malformations: review. Neurol India 52:43-53, 2004

22. Halbach VV, Dowd CF, Higashida RT, Balousek PA, Ciricillo SF, Edwards MS: Endovascular treatment of mural-type vein of Galen malformations. J Neurosurg 89:74-80, 1998

23. Hanner JS, Quisling RG, Mickle JP, Hawkins JS: Gianturco coil embolization of vein of Galen aneurysms: technical aspects. Radiographics 8:935-946, 1988

24. Hassan T, Nassar M, Elghandour M: Vein of Galen aneurysms: presentation and endovascular management. Pediatr Neurosurg 46:427-434, 2010

25. Heuer GG, Gabel B, Beslow LA, Stiefel MF, Schwartz ES, Storm PB, et al: Diagnosis and treatment of vein of Galen aneurysmal malformations. Childs Nerv Syst 26:879-887, 2010

26. Hoffman HJ, Chuang S, Hendrick EB, Humphreys RP: Aneurysms of the vein of Galen. Experience at The Hospital for Sick Children, Toronto. J Neurosurg 57:316-322, 1982

27. Iizuka Y, Kakihara T, Suzuki M, Komura S, Azusawa H: Endovascular remodeling technique for vein of Galen aneurysmal malformations - angiographic confirmation of a connection between the median prosencephalic vein and the deep venous system. J Neurosurg Pediatr 1:75-78, 2008

28. Iizuka Y, Maehara T, Katayama H, Sato K, Kugimiya T, Yamashiro Y: Endovascular treatment of vein of Galen aneurysmal malformations. Interv Neuroradiol 4 (Suppl 1):109-112, 1998

29. Johnston IH, Whittle IR, Besser M, Morgan MK: Vein of Galen malformation: diagnosis and management. Neurosurgery 20:747-758, 1987

30. Jones BV, Ball WS, Tomsick TA, Millard J, Crone KR: Vein of Galen aneurysmal malformation: diagnosis and treatment of 13 children with extended clinical follow-up. AJNR Am J Neuroradiol 23:1717-1724, 2002

31. Khullar D, Andeejani AM, Bulsara KR: Evolution of treatment options for vein of Galen malformations. J Neurosurg Pediatr 6:444-451, 2010

32. Komiyama M, Nakajima H, Nishikawa M, Yamanaka K, Iwai Y, Yasui T, et al: Vein of Galen aneurysms. Experience with eleven cases. Interv Neuroradiol 7 (Suppl 1):99-103, 2001

33. Lasjaunias P, Garcia-Monaco R, Rodesch G, Ter Brugge $\mathrm{K}$, Zerah M, Tardieu M, et al: Vein of Galen malformation. Endovascular management of 43 cases. Childs Nerv Syst 7:360-367, 1991

34. Lasjaunias P, Hui F, Zerah M, Garcia-Monaco R, Malherbe V, Rodesch G, et al: Cerebral arteriovenous malformations in children. Management of 179 consecutive cases and review of the literature. Childs Nerv Syst 11:66-79, 1995

35. Lasjaunias P, Rodesch G, terBrugge KG, Pruvost P, Devictor $\mathrm{D}$, Comoy J, et al: Vein of Galen aneurysmal malformations. Report of 36 cases managed between 1982 and 1988. Acta Neurochir (Wien) 99:26-37, 1989

36. Lasjaunias PL, Chng SM, Sachet M, Alvarez H, Rodesch G, Garcia-Monaco R: The management of vein of Galen aneurysmal malformations. Neurosurgery 59 (5 Suppl 3):S184S194, S3-S13, 2006 [Erratum in Neurosurgery 60 (4 Suppl 2):393, 2007]

37. Li AH, Armstrong D, terBrugge KG: Endovascular treatment of vein of Galen aneurysmal malformation: management strategy and 21-year experience in Toronto. J Neurosurg Pediatr 7:3-10, 2011

38. Lylyk P, Viñuela F, Dion JE, Duckwiler G, Guglielmi G, Peacock W, et al: Therapeutic alternatives for vein of Galen vascular malformations. J Neurosurg 78:438-445, 1993 
39. McSweeney N, Brew S, Bhate S, Cox T, Roebuck DJ, Ganesan V: Management and outcome of vein of Galen malformation. Arch Dis Child 95:903-909, 2010

40. Meila D, Hannak R, Feldkamp A, Schlunz-Hendann M, Mangold A, Jacobs C, et al: Vein of Galen aneurysmal malformation: combined transvenous and transarterial method using a "kissing microcatheter technique". Neuroradiology $\mathbf{5 4 : 5 1 - 5 9 , 2 0 1 2}$

41. Mitchell PJ, Rosenfeld JV, Dargaville P, Loughnan P, Ditchfield MR, Frawley G, et al: Endovascular management of vein of Galen aneurysmal malformations presenting in the neonatal period. AJNR Am J Neuroradiol 22:1403-1409, 2001

42. Moon JH, Cho WS, Kang HS, Kim JE, Lee SJ, Han MH: Vein of Galen aneurysmal malformation: endovascular management of 6 cases in a single institute. J Korean Neurosurg Soc 50:191-194, 2011

43. Norman MG, Becker LE: Cerebral damage in neonates resulting from arteriovenous malformation of the vein of Galen. J Neurol Neurosurg Psychiatry 37:252-258, 1974

44. Payne BR, Prasad D, Steiner M, Bunge H, Steiner L: Gamma surgery for vein of Galen malformations. J Neurosurg 93:229-236, 2000

45. Pongpech S, Aurboonyawat T, Visudibhan A, Jiarakongmun $P$ : Endovascular management in children with vein of Galen aneurysmal malformation. Minim Invasive Neurosurg 53:169-174, 2010

46. Rodesch G, Hui F, Alvarez H, Tanaka A, Lasjaunias P: Prognosis of antenatally diagnosed vein of Galen aneurysmal malformations. Childs Nerv Syst 10:79-83, 1994

47. Sterne JA, Egger M: Funnel plots for detecting bias in metaanalysis: guidelines on choice of axis. J Clin Epidemiol 54:1046-1055, 2001
48. Sterne JA, Egger M, Smith GD: Systematic reviews in health care: Investigating and dealing with publication and other biases in meta-analysis. BMJ 323:101-105, 2001

49. Watban JA, Rodesch G, Alvarez H, Lasjaunias P: Transarterial embolization of vein of Galen aneurysmal malformation after unsuccessful stereotactic radiosurgery. Report of three cases. Childs Nerv Syst 11:406-408, 1995

50. Wong FY, Mitchell PJ, Tress BM, Dargaville PA, Loughnan PM: Hemodynamic disturbances associated with endovascular embolization in newborn infants with vein of Galen malformation. J Perinatol 26:273-278, 2006

51. Zuccaro G, Argañaraz R, Villasante F, Ceciliano A: Neurosurgical vascular malformations in children under 1 year of age. Childs Nerv Syst 26:1381-1394, 2010

\section{Author Contributions}

Conception and design: Yan, Wen. Acquisition of data: Yan, Zhang. Analysis and interpretation of data: Yan, Gopaul. Drafting the article: Yan. Critically revising the article: Xiao, Yan, Zhang. Reviewed submitted version of manuscript: Wen, Gopaul. Approved the final version of the manuscript on behalf of all authors: Xiao. Statistical analysis: Wen. Administrative/technical/ material support: Xiao. Study supervision: Xiao.

\section{Correspondence}

Shao-wen Xiao, Neurosurgery Department, The First Affiliated Hospital of Guangxi Medical University, Shuang Yong Rd. No. 6, Nanning, Guangxi Province 530021, PR China. email: xiaoshaowen2014@126.com. 